\title{
WHAT IS INCLUSION AND HOW IS IT INFLUENCED BY ADMINISTRATION: NARRATIVES FROM 3 EARLY CHILDHOOD EDUCATORS
}

by

Warda Batool, BA, Ryerson University, 2018

An MRP
presented to Ryerson University

in partial fulfillment of the

requirements for the degree of

Masters of Arts

in the Program of

Early Childhood Studies

Toronto, Ontario, Canada, 2020

(C) Warda Batool 2020 


\section{AUTHOR'S DECLARATION FOR ELECTRONIC SUBMISSION OF A MRP}

I hereby declare that I am the sole author of this MRP. This is a true copy of the MRP, including any required final revisions.

I authorize Ryerson University to lend this MRP to other institutions or individuals for the purpose of scholarly research

I further authorize Ryerson University to reproduce this MRP by photocopying or by other means, in total or in part, at the request of other institutions or individuals for the purpose of scholarly research.

I understand that my MRP may be made electronically available to the public. 


\title{
ABSTRACT \\ WHAT IS INCLUSION AND HOW IS IT INFLUENCED BY ADMINISTRATION: NARRATIVES FROM 3 EARLY CHILDHOOD EDUCATORS
}

\author{
Masters of Arts, 2020 \\ Warda Batool \\ Program of Early Childhood Studies, \\ Ryerson University
}

Through this study, I aimed to explore ECEs perceptions of inclusion and their perspectives on how their understandings and practice are influenced by the administration at their work setting. I used theories from Disability Studies to shape my study and analyze my findings. I sampled 3 participants, 2 of whom were previous ECEs and 1 who was currently an ECE. I held 3 individual interviews where I used an interview guide to ask ECEs about their stories around the research questions. Then, using thematic coding and inductive reasoning, I arrived with 3 themes; definitions of disability, perceptions of inclusion, and understandings and opinions towards administration. I discussed the findings while arguing that ECEs definitions of disability influence their perceptions of inclusion. Which then leads them to seek specific supports from administration. I used these discussions to humbly suggest some implications for ECEs. 


\section{ACKNOWLEDGEMENTS}

Dr. Esther Ignagni, thank you for supporting me through this journey as my supervisor and accommodating my needs as a learner. I truly appreciate all the time you have dedicated to my work, our weekly meetings, and your kind words of encouragement.

Dr. Kathryn Underwood, as my second reader, I appreciate all the time you spent on my MRP, your feedback as a knowledgeable member of disability and education and your encouragement that pushed me to write something that I can be proud of.

My family and friends, thank you for always supporting me, being proud of my achievements, and showing interest in my work!

Mohammed, thank you for always supporting me with your words and actions. Thank you for pushing me to take pride in myself, my work, and my journey. 


\section{DEDICATION}

To L, thank you for inviting me to think about education and care beyond my comfort and convenience. 


\section{TABLE OF CONTENTS}

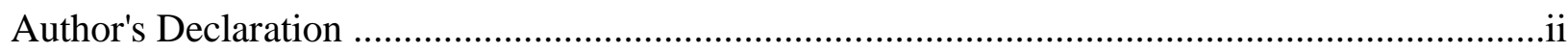

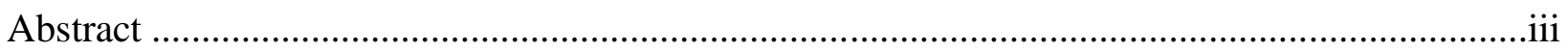

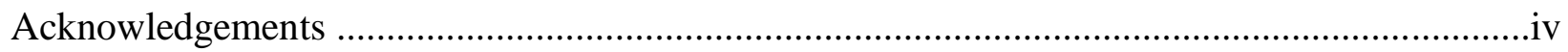

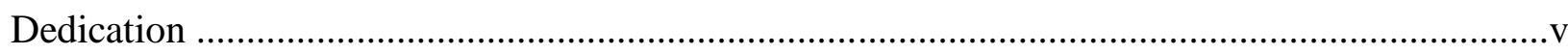

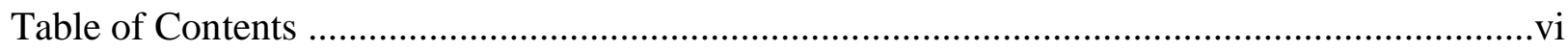

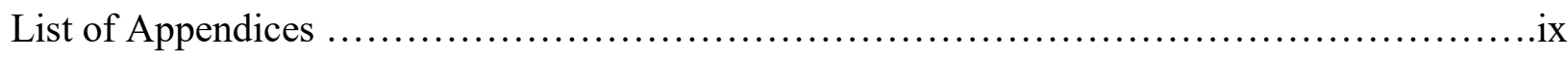

\section{Chapter I: Introduction and Review of Literature}

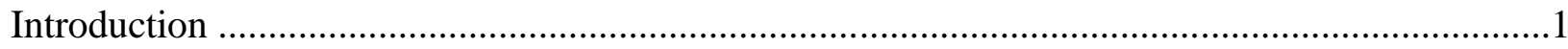

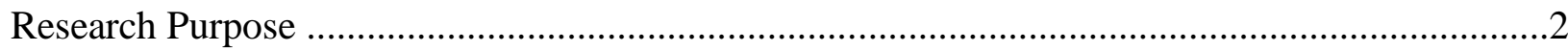

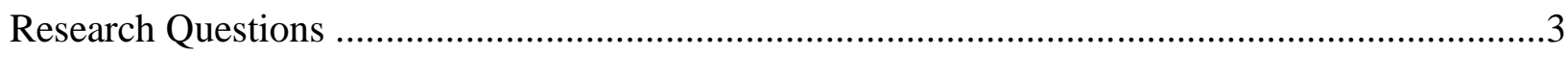

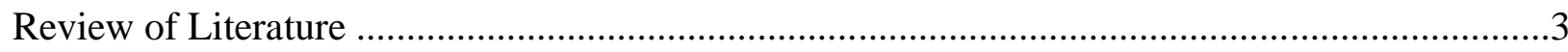

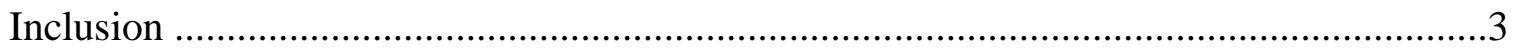

Educators' Perceptions of Inclusion.........................................................................

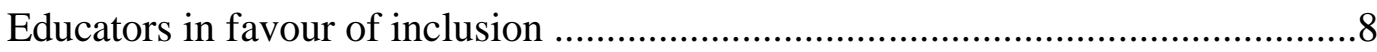

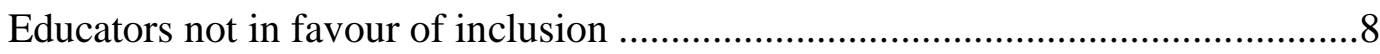

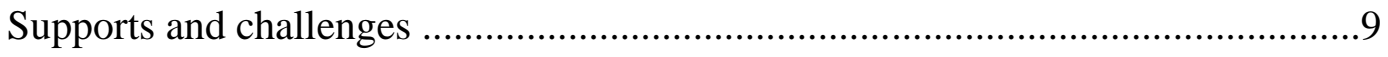

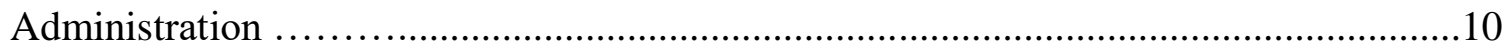

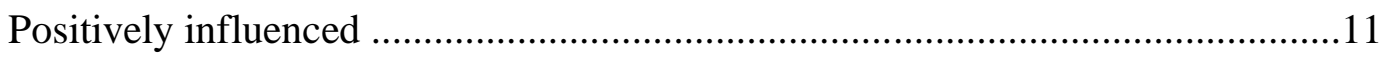

Negatively influenced ………………...........................................................11

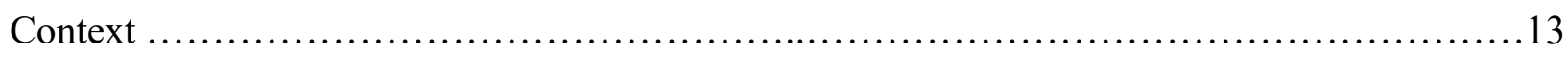

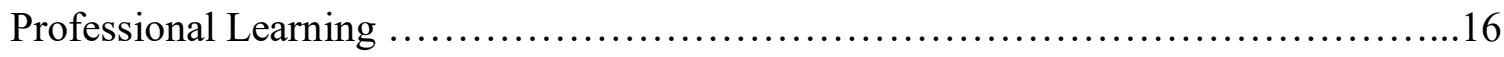

Childcare Administration in Ontario ............................................ 17 


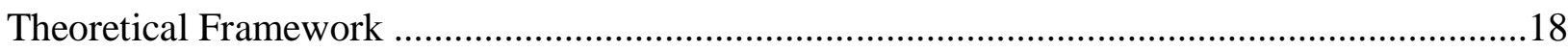

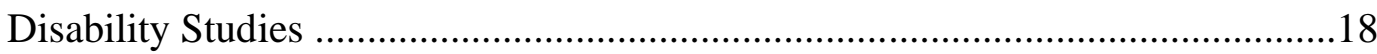

Critical Disability Studies ................................................19

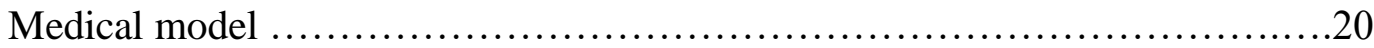

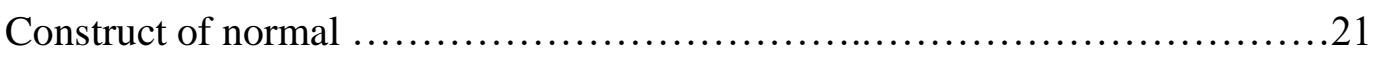

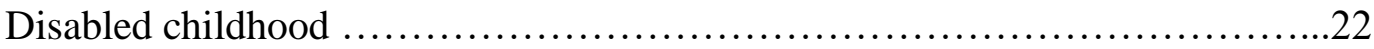

\section{Chapter II: Methodology}

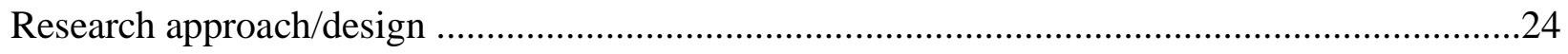

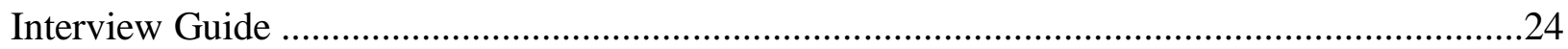

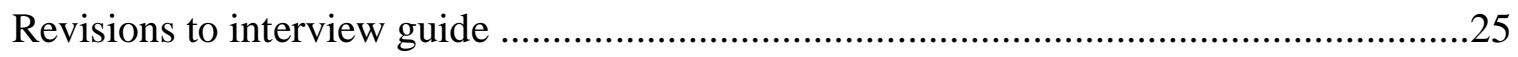

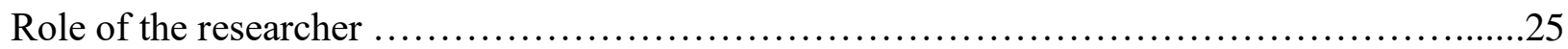

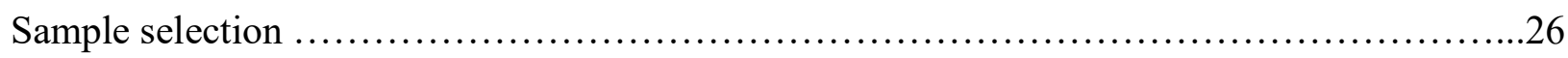

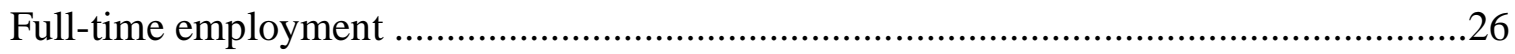

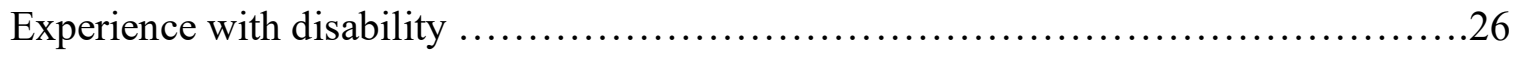

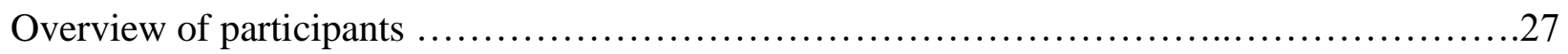

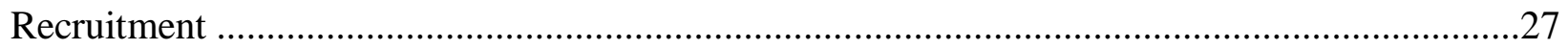

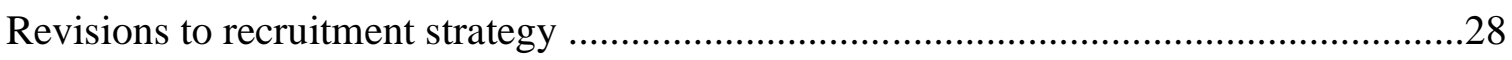

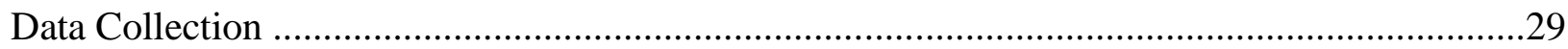

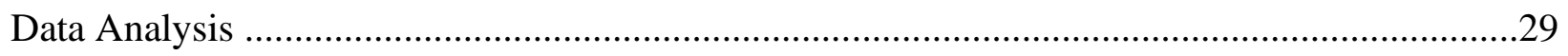

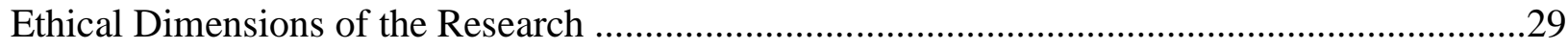

\section{Chapter III: Findings}

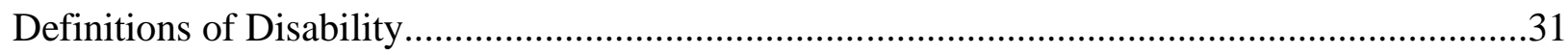

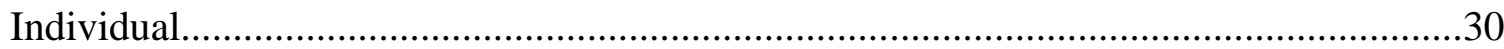




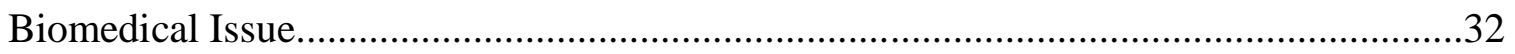

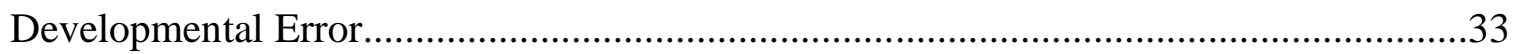

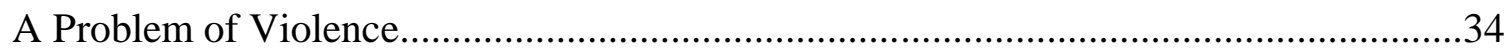

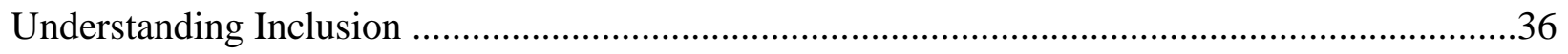

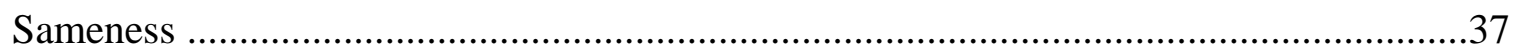

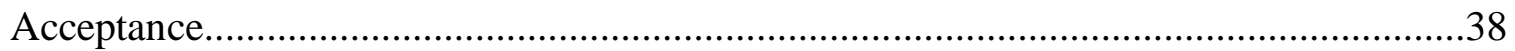

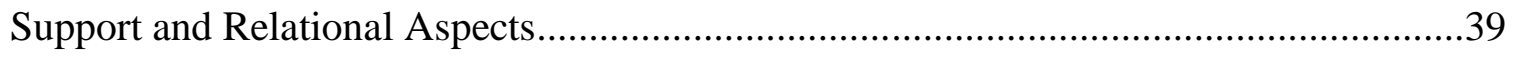

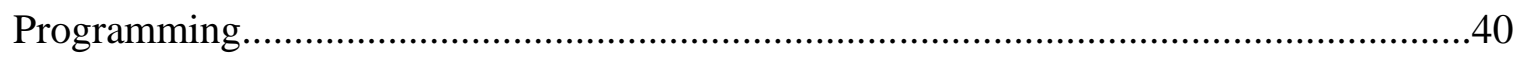

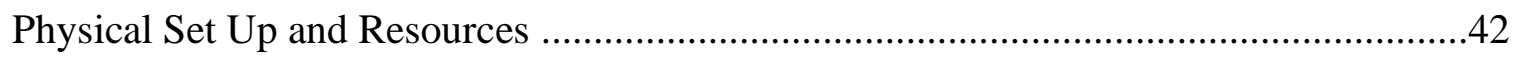

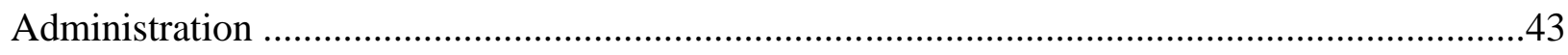

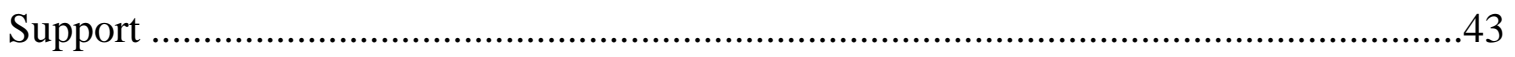

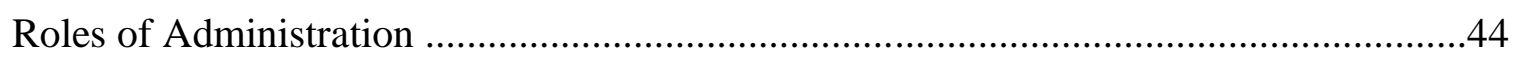

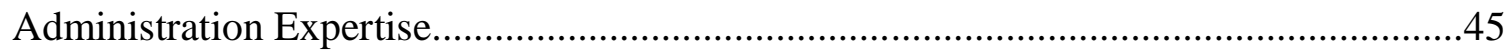

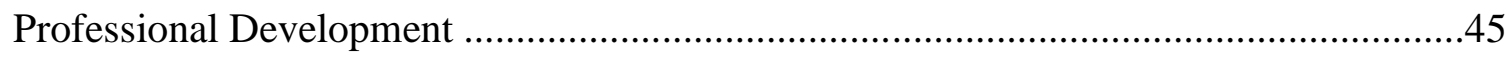

Perspectives of ECEs towards Administration...................................................46

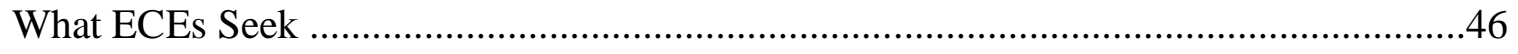

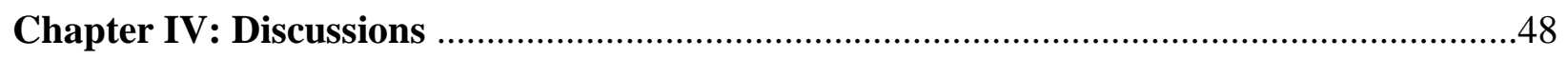

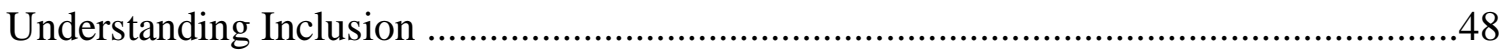

What Participants Seek from Administration ......................................................50

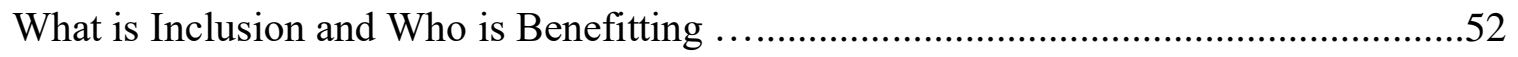

\section{Chapter V: Implications and Limitations}

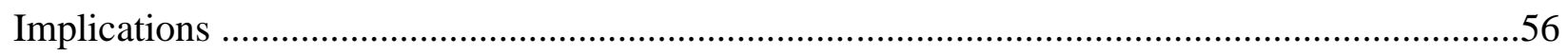

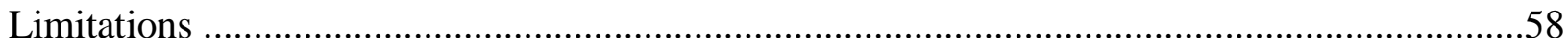


Conclusion

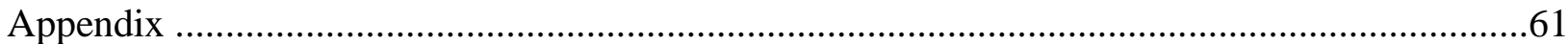

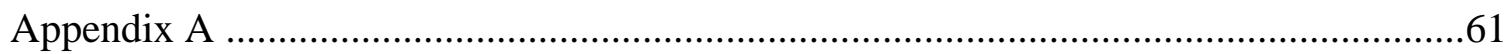

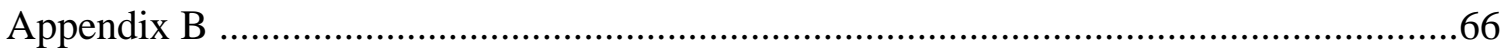

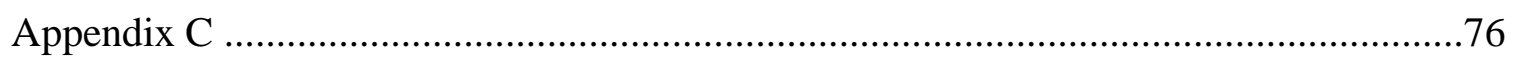

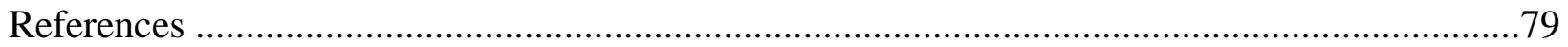




\section{LIST OF APPENDICES}

Appendix A - Ryerson University Consent Letter

Appendix B - Recruitment Flyer

Appendix C - Interview Guide
Page \# 61

Page \# 66

Page \# 76 


\section{CHAPTER 1. INTRODUCTION}

Inclusion in early learning settings is becoming increasingly relevant in both policy and practice (Friendly, 2004). A learning approach that offers support in the classroom with a fairer distribution of opportunities for all children is now widely considered and claimed to be a standard of practice in many countries (Balakrishnan et al, 2019; Das, Gichuru, \& Singh, 2013; Dreyer, 2013; McCrimmon, 2015; Suc, Bukovec, Zveglic, \& Karpljuk, 2016). After the paper by the United Nations Educational, Scientific and Cultural Organization (1994) to shift educational practices from specialized education to inclusive education, early childhood education and care (ECEC) professionals in Ontario are advocating more for inclusive practice. For the purpose of this paper, I discuss inclusion exclusively in terms of including children who are perceived as outside of typical development by the dominant society (Curran \& Runswick-Cole, 2014). In Ontario, The Ministry of Education advocates for inclusive practice in each licensed early learning centre and inclusive education (IE) has been implemented in an effort to meet the needs of many students (McCrimmon, 2015). However, there are many challenges in the classroom for IE after years of segregation of children with 'lower' abilities including educators' skills and self-perceptions in responding to a change in practice (McCrimmon, 2015).

I question whether perceptions of inclusion in early learning settings match real definitions of inclusive practice. How do professionals perceive inclusion, as these understandings influence practice which then impacts the experiences of all children in their care? Although there are scales such as SpeciaLink Early Childhood Inclusion Quality Scale (Irwin, 2019), to paint a picture of what inclusion can look like, Ishimine, Taylor and Thorpe (2009) argue that perceptions of inclusion can vary by each centre depending on the values of 
their staff. I argue that it is necessary to explore how inclusion is perceived by individual early childhood educators (ECE) in order to understand the early learning experiences of children with disabilities.

In a Ministry of Education document, Underwood (2013) states that inclusion consists of three main components: policies that promote inclusion, leadership that supports inclusion, and staff that value inclusion. Through the combination of these structures, there can be more inclusive practices in ECEC. For this study, two of the three components offered by Underwood (2013) were explored, specifically investigating how leadership and administrative practices impact staff and educators in the area of inclusive practice. This study's findings and their discussion have directed some suggestions and implications around disability and inclusion for ECEs.

\section{Research Purpose}

The purpose of this research was to explore how current or previous ECEs in Ontario understand and practice inclusion, and their perceptions of how administration at their current and/or previous centres impact their understanding and practice of inclusion. This study is a Master's Research Paper (MRP) for the School of Early Childhood Studies, Ryerson University. These data will be used to suggest implications for ECEs around inclusive practice.

In this paper, ECEs perceptions and narratives will be primarily considered as they contribute a large role to inclusive practice (Damianidou \& Phiaka, 2018) and staff that value inclusion are a major component in IE (Underwood, 2013). The incentive for proposing this study is directly related to my experiences in early learning settings where I experienced an absence of true inclusive practice and tensions between the link of administration impacting 
inclusive practice. Therefore, this study was initiated to explore the understandings ECEs hold about inclusive practice and their perceptions of how administration shapes their understandings and practice when considering the inclusion of children with disabilities in early learning settings.

Themes explored in the literature reviewed for this study were: perceptions of inclusion (Damiandou and Phiaka, 2018; Dreyer, 2013); Horne and Timmons, 2009; McLesky and Waldron, 2002; Norrell, 1997; Suc, Bukovee, Zveglic, and Karpljuk, 2016; Zagona, Kurth, and MacFarland, 2017), teacher attitudes towards inclusion (Dreyer, 2013; Suc, Bukovee, Zveglic, \& Karpljuk, 2016; Horne and Timmons, 2009; McLesky and Waldron, 2002), and administrative influence on inclusive practice (Damianidou \& Phiaki, 2018; Horne and Timmons, 2009; Lehr, 1999; Marvin, LaCost, Grady, \& Mooney, 2003; Shady, Luther, and Richman, 2013). Relevant gaps in the literature included: the perceptions and understandings of ECEs in specific and in relation to the relationship between inclusion and administration. Therefore, in this study, I decided to primarily focus on educators in the field of ECEC due to its relevancy to my field of study.

\section{Research Questions}

This study aimed to explore the following questions: how do ECEs perceive inclusive practice? How do ECEs perceive administration to be influencing their understandings and practices of inclusion? What do ECEs wish for from their administration?

\section{Review of Literature}

\section{Inclusion}

According to the Ministry of Education (2015), inclusion happens when early year programs are accessible to all children and families and are specifically designed for the 
individual needs of all children while also being committed to continuous program monitoring to ensure inclusive practice. Although this definition and similar ones primarily shape the way inclusion is defined in this study, I should note that inclusion is not always defined in one way. And sometimes, the term inclusion is used interchangeable with other terms such as integration that are much different by definition (Harman, 2014). I found it critical to review the literature around this term in order to explore structures that influence varying definitions. I arrived with major definitions. Such as inclusion as equal opportunity (Zagona, Kurth, and MacFarland, 2017), inclusion as a transformation of philosophy, values, and practice (Dreyer, 2013), inclusion as in class support (Horne \& Timmons, 2009), and inclusion as a systemic concern (Damiandou \& Phiaka, 2018; Suc, Bukovee, Zveglic, and Karpljuk, 2016).

Zagona, Kurth, and MacFarland (2017) stated that inclusion is when the learning opportunities of students with disabilities are more aligned with the general class. Dreyer (2013) shares that IE is more than just simply assigning children with learning impairments or other barriers into a general environment with typically developing peers. Rather it is a transformation of one's philosophy, values and practices. Horne and Timmons (2009) claimed that serving students with a full range of abilities and disabilities in the general education classroom requires appropriate in-class support.

Other perspectives or definitions appeared to challenge systemic issues, where they looked at inclusion as not only inside an individual classroom, but rather within a larger system. Suc, Bukovee, Zveglic, and Karpljuk (2016) state that the quality of inclusion in one class reflects the quality of the entire system, which then further reflects on inclusion in the larger society. According to this perspective, if individual classes do not reflect inclusive practice, then neither does the school or program, thus, meaning the larger society also does not. Damiandou 
and Phiaka (2018) define inclusion as a larger social issue by suggesting that inclusive practices that begin in the classroom lead to the distribution of equal opportunities and social justice among all individuals in the larger society.

McLesky and Waldron (2002) argued to consider larger structures when thinking about inclusion. In their work, they stated that it is not only the attitudes and values of individual educators, but the attitudes of the overall system of the school/centre that must be considered. They suggested continual challenge of the conceptions of normalcy that reinforce the individual model in education, that only have room for 'fixing' disability rather than embracing it. They go on to say that through understandings of critical disability theory, if practices of an educator need to change within a classroom, then the entire system must also experience that shift. Although this was not explored further in their work with an actual research sample, it points us in the direction where we can consider systems in early childhood settings that are influential to change, such as administration.

Lastly, McLesky and Waldron (2002) drifted focus solely from individuals with disabilities by stating that inclusion no longer only considers those who are deemed as 'special' but rather focuses on improving education for all students. The implication of this shift would mean seeing inclusion for all rather than just a selected number of children.

\section{Educator's Perceptions of Inclusion}

Educators beliefs and perceptions around inclusion are a significant contributor to the practice of inclusion (Bruns \& Mogharreban, 2007; Underwood, 2013). Due to this claim, I found it appropriate to explore educators' understandings and perceptions of inclusion. A review of the literature revealed differing definitions of inclusion and differing attitudes towards inclusive practice (Dreyer, 2013; Edmunds, 1998; Horne \& Timmons, 2009; McLesky and 
Waldron, 2002; Suc, Bukovee, Zveglic, \& Karpljuk, 2016). Some educators were in favour of inclusion, some were not in favour, and some were in favour but expressed the need for support. In Majoko's (2016) study, some participants shared their definitions of inclusion through sharing what they seek support in. Majoko's (2016) participants felt ill prepared to practice inclusion even after receiving training on inclusive education. One participant stated, "We need to learn about all types of disabilities and their management in mainstream classrooms" (Majoko, 2016, 1866). It seems that participants felt the need for more specialized knowledge on disability and disability 'management.' They stated that they feel incompetent in adapting their teaching to accommodate children with disabilities. They also believed that the physical environment was also not responsive to different needs and was not accessible. These participants seemed to understand the environment as significant to successful inclusion but also showed preference to specialized knowledge on disabilities that imply a biomedical influenced understanding of disability (Brisenden, 1986; Fisher \& Goodley, 2007). Similarly, one ECE from Frankel, Hutchinson, Burbidge, \& Minnes' (2014) study shared that she was challenged on how to prepare a teaching plan if she did not know if a child was diagnosed or not. Her perception of inclusion relied on the labelling of the child.

Gunilla and Claes's (2014) participants also seemed to understand the significance of inclusion and offered a positive attitude towards it. All participants identified implementing supports for children inside the classroom as crucial to inclusion. Additionally, the teachers also stated that they need to constantly evaluate the classroom environment, such as their attitudes, resources, and practices, to promote inclusion. Although participants from Gunilla and Claes's (2014) study had differentiating definitions of inclusion, for example, some said inclusion does not depend on students being inside or outside the classroom and some said that inclusion is not 
just for students with disabilities, they all believed that inclusion involved the student being part of the class or group on their own terms. Additionally, teachers also stated that only children aimed to be included were people who could judge inclusion (Gunilla \& Claes, 2014). These participants seemed to look at inclusion through a lens supported by critical disability studies as they seek to understand inclusion by the person who is or is not experiencing it (Reaume, 2014).

In Majoko's (2016) study, 16 participants defined inclusion as a philosophy that should guarantees the right of both disabled and nondisabled children to have access to the same kind of pedagogical content, process and assessment that is responsive to their individual needs, and the same educational settings. The other 8 participants defined inclusion through a rights based approach. Stating that all children regardless of ability have the right to an education that accommodates their needs in the same environment as everyone else (Majoko, 2016).

In Frankel, Hutchinson, Burbidge, and Minnes' (2014) research study, educators working with children who have developmental disabilities and delays (DDD) shared their ideas and reallife examples of successful inclusion, including differentiated teaching and collaborative interactions with other adults. Participants stated that differentiated instruction involved adapting teaching strategies, providing modified activities, and using adaptive technologies (Frankel, Hutchinson, Burbidge, \& Minnes, 2014). Collaborative interactions with other adults involved those with individuals such as resource teachers, interventionists and parents (Frankel, Hutchinson, Burbidge, \& Minnes, 2014). These ECEs seemed to understand the influence relations and structures in the environment had on inclusive practice and adapted these systems to practice inclusion. 


\section{Educators in favour of inclusion.}

Killoran, Woronko, and Zaretsky (2014) presented teachers and ECEs with several statements related to children with disability and inclusive practice. Their findings indicated that the majority of both teachers and ECEs had positive attitudes towards inclusion. Most participants always disagreed with negative statements and agreed with positive ones. For example, $72 \%$ of teachers and $81 \%$ of ECEs disagreed with the statement "The contact students without a disability have with a student with a disability in an inclusive setting may be harmful" (Killoran, Woronko, \& Zaretsky’s, 2014, 435).

Majoko (2016) claimed that the ECEs' positive attitude towards inclusion was influenced by participants knowledge on the benefits of inclusion for both disabled and nondisabled children. The participants from Bruns \& Mogharreban's (2007) study also held positive attitudes towards inclusion. ECEs strongly believed that all children can learn and that children with disabilities and children without disabilities are more similar than different. Majority of the participants believed that children with disabilities should receive services alongside their typical peers in general classrooms. However, the context around services was unclear.

\section{Educators not in favour of inclusion.}

Dreyer (2013) claimed that although there has been a shift from a traditional and individual model of special education to an 'education for all' approach, where different levels of support needed within the general classrooms are encouraged, teacher behaviours and values still reflect the deep roots of the long established individual model, where one believes the disability lies solely within the individual's physical, emotional, and intellectual self (Fisher \& Goodley, 2007). Dreyer (2013) stated that these traditional values are reflected through the consistent practice of the withdrawal technique used by many teachers, where students who are labelled 
'delayed', or who exhibit academic differences, are withdrawn from the general classroom during specific subjects such as literacy or math, for individualized instruction and support. Although we understand withdrawing disabled children from their class as not aligning with inclusive practice (Dreyer, 2013), there is a need to understand the influences of this preference. This gap could be assessed through dialogue directly with the educators who prefer this technique.

In Suc, Bukovee, Zveglic, and Karpljuk's (2016) study, most educators seemed to view disability with an individual model and only $20 \%$ of participants saw disability through a social model. Where disability is understood as the result of attitudes and structures of the environment rather than the self (Goodley, 2001). This resulted in more educators expecting change in individual disabled children rather than altering the environment to accommodate for their needs.

Findings from Huang and Diamond's (2009) study revealed preference towards inclusion depended on the children. Their findings suggested that teachers held more positive attitudes about including a child with a disability involving motor skills, such as cerebral palsy, than a child with learning, language or behavioural disability(s). Additionally, it seemed that teachers

least preferred including children with severe intellectual disabilities (Huang \& Diamond, 2009). However, one could argue that there is no inclusion here at all if not all children are included.

\section{Support \& challenges.}

Teachers also expressed need for support and explained challenges related to inclusion (Bruns \& Mogharreban, 2007; Frankel, Hutchinson, Burbidge, \& Minnes, 2014; Horne \& Timmons, 2009; Suc, Bukovee, Zveglic, and Karpljuk, 2016). In Suc, Bukovee, Zveglic, and Karpljuk's (2016) study, some participants had a favourable approach towards inclusion. However, they believed that IE needed lots of support. Further exploration around support was 
not considered by the researchers, but it may have possibly started with the administration at participant's early learning centre. For example, in Horne and Timmons' (2009) study, the overall sample of general educators agreed with the idea that students with disabilities should be fully included into general classrooms and the importance of creating a learning environment fit for all students, however, they claimed that their perspectives may only be applicable if matched with appropriate support. In Bruns \& Mogharreban's (2007) study, although participants seemed to be in favour of inclusion, very few participants agreed that inclusion was always possible and easy to implement. This response could have been influenced by ECEs feelings of unpreparedness as amongst all participants, there was indication to seek more training on behavioral issues, communication strategies, handling and positioning (Bruns \& Mogharreban, 2007).

Some participants thought it was challenging to practice inclusion in settings where there were opposing beliefs. One participant stated it was hard for her to practice inclusion when her co-teacher preferred taking children out of the class if they 'acted out' (Frankel, Hutchinson, Burbidge, \& Minnes, 2014).

\section{Administration}

In this section, I directed attention on educators' perceptions on how administration influences their understandings and practice of inclusion. According to Lehr (1999), the administrative teams in schools have specific responsibilities and they generally represent the school's attitude. Roles of administration might include ensuring appropriate professional growth, assigning planning time, training for effective collaboration, and policy creation and maintenance (Lehr, 1999). Marvin, LaCost, Grady, and Mooney (2003) added that addressing the concerns of staff, establishing an attitude that represents the staff and families, and 
networking with appropriate agencies in the community are also significant duties. If these duties are practiced, then Ruairc, Ottesen, and Precey (2013) would argue that there is a link between administration and teacher practice. According to the literature reviewed for this study, educators also seem to believe that administration has an influence on inclusive practice. However, there were varying opinions on whether this influence was positive or negative.

\section{Positively influenced.}

In Shady, Luther, and Richman's (2013) research, 13 of the 34 participating educators stated that they received some of the necessary support from their administrative team which lead to effective implementation of inclusive practices. However, specifics on what supports lead to successful practice were not captured. In Marvin, LaCost, Grady, and Mooney’s (2003) study, more than two-thirds of the 176 early childhood (EC) teachers surveyed claimed that their administrative staff held effective knowledge, advocated for their EC program and supported them appropriately with flexible work schedules and time with families for the in-home programs. This lead to success in their own practice. Most participants from Woodcock \& Woolfson's (2019) study suggested that systemic support in the subcategories of leadership, professional development, and budgets positively impacted inclusion.

\section{Negatively influenced.}

From Shady, Luther, and Richman's (2013) study, majority of the participants surveyed stated that they did not have enough time to communicate or collaborate with other professionals in regard to their ideas or opinions around inclusive practice, which lead to ineffectiveness in their attempts to practice inclusion (Shady, Luther, \& Richman, 2013). Such as tensions between staff, unclear understandings of goals and strategies, and inconsistency in practice (Shady, Luther, \& Richman, 2013). Results from the focus group with the participants also displayed 
similar opinions, as they expressed that the administrative team needed to allocate more time for professionals to collaborate with each other. Similarly, some participants from Woodcock \& Woolfson's (2019) study expressed that they had lack of support from leaders and administration at their schools and that problems were only dealt with after arising.

A study from Cyprus gathered 536 questionnaires and 21 interviews from educators in settings that are newly adopting inclusion (Damianidou \& Phiaki, 2018). The results indicated that educators believed they were provided with inadequate teacher training to progress their skills and knowledge for inclusive practices, a non-existent curriculum that is suited for working with children with special needs, and scarce supplies of equipment used for support (Damianidou \& Phiaki, 2018). Educators noted that collaboration with specialists to create inclusive environments could perform miracles, if only they were given the appropriate supports to do so (Damianidou \& Phiaki, 2018). These educators claimed to have favourable attitudes towards inclusion but faced administrative barriers in achieving inclusive practices. Participants from Horne and Timmons' (2009) study also had concerns around administrative barriers. For example, they raised concerns regarding planning time as they believed adequate time is needed to adapt curriculum to fit all children's needs which would maintain inclusive practices. Most educators agreed that allocation of planning time fell under the responsibility of the administrative staff.

According to the literature reviewed, educators almost always believed that administration influenced their practice around inclusion. However, there were mixed opinions of whether this impact was beneficial or harmful to inclusion. In some studies, educators indicated both positive and negative impacts. Most of the educators sampled in the discussed studies belonged to classrooms of elementary or secondary schools, so the perspectives of ECEs 
appeared minimal in the literature reviewed for this study. However, the findings that were apparent in the literature only motivated me to explore administration further in this study through open-ended questions with ECEs.

\section{Context}

Early Childhood Education and Care in Canada involves various settings including childcare, preschool, kindergarten, and home-based care (Underwood \& Frankel, 2012). In this study, all participants spoke about privatized childcare centres. This section will discuss the settings where participants in this study worked, and the contexts within which their childcare programs operated. This will also include current discourse about inclusion, the context of ECE's practice and professional standing in Ontario, and the administrative structures of each child care centre in Ontario.

Participants in this study were or had been previously employed at for-profit childcare centres. Although a report from the Ministry of Education (2019) declared that the majority of childcare centres in Ontario are not-for-profit, there are still many centres that run as for-profit (Friendly \& Prentice, 2009). The concept of childcare had first emerged and spread quickly during the period of 1965-1985 for mothers participating in the labour force and other economic and political impacts (Tuominen, 1991). During this time, privatization dominated the field. Tuominen (1991) would argue that in the midst of women's' labour rights, issues of neoliberal agenda are camouflaged. Currently, in Ontario, childcare is available to families as a service on the market with the neoliberal reasoning that "human well-being can best be advanced by liberating individual entrepreneurial freedoms and skills within an institutional framework characterized by strong private property rights, free markets, and free trade" (Harvey, 2005, p. 
2). In other words, childcare is to be understood as a service that a family/consumer can purchase from a selection of private businesses that offer the best quality of childcare.

Childcare in Ontario is not offered as a Universal system. This fact is significant to our discussion around inclusion because there seems to be a relationship between the two. According to Buysse and Hollingsworth (2009), there is a link between high quality programs and inclusion. A greater program quality can promise more inclusive practices for all children in the setting (Buysse \& Hollingsworth). Prior to the 1984 Federal election, there was some hope of non-profit nationwide childcare because of the 1983 'Equality in Employment: A Royal Commission Report' which proposed that the absence of affordable childcare is a barrier for women trying to achieve workplace equality (Tuominen, 1991). Additionally, the establishment of the Cooke Task Force that advocated for a national childcare strategy also proposed direction towards a universal strategy. The experts on this task force suggested for both federal and provincial structures to collaborate in the childcare system and for the federal government to take a leading role (Friendly, 2006) to say the least. However, the election of the Conservative government under Prime Minister Brian Mulroney followed a path favouring childcare through a business lens (Tuominen, 1991) which is largely seen today even after changing elected federal parties. Therefore, it is important to note that ECEs in this study, and the administration they speak about, are working within a childcare system that exists as a business service to consumers. Their practices of inclusion may have been impacted by this context.

The concept of 'inclusion' is defined in several policy documents in Ontario and interpretations of it vary across literature (Underwood, 2006). Which is important in understanding the ways in which this study's participants talk about inclusion and disability. Documents such as Everyone is Welcome: Inclusive Early Childhood Education and Care 
(Underwood, 2013) and Inclusion: Policy Development Guidelines for Early Learning and Care Programs (City of Toronto, 2007) encourage the creation and practice of policies that promote inclusive education. According to these documents, centres should adhere to access not only within the centre, in the form of physical resources, but also to other programs such as early intervention, family support, housing, income security and employment, culturally specific services and immigration services (Underwood, 2013).

As stated earlier, inclusion can be interpreted in different ways. Educators may also be unaware of their own theoretical understandings around inclusion (Zaretsky, 2005). For example, inclusion is sometimes thought to be the same as integration (Allan, 2005). However, by definition, the latter means the integration of children with perceived special needs into regular classrooms (Schanin \& Reiter, 2007) and is not quite the same as inclusive practice which aims to provide a curriculum that is responsive to the learning needs of all the children in the room (Bunch et al., 2005). Inclusive practice is also sometimes considered to be the addition of specialized knowledge in a regular classroom. However, Slee and Allan (2001) would argue against this notion stating that specialized education emphasizes individual differences which seek to be treated within the individual person.

How Does Learning Happen (Ministry of Education, 2014) speaks on inclusion and inclusive practice many times throughout the document. This document is largely used in early learning and care settings in Ontario, making their definition of inclusion significant to this study. How Does Learning Happen (Ministry of Education, 2014) firstly uses principle 3 from the document Early Learning for Every Child Today (Ministry of Education, 2007) to claim inclusion as vital and beneficial to all children (Ministry of Education, 2014). Inclusion is defined as an environment that is specifically designed to foster every child's well-being, 
learning, and development and ensure their meaningful participation. This environment would encourage exploration, play and inquiry while also being a foundation to building positive relationships with children, families, colleagues and the community (Ministry of Education, 2014). Guidelines for educators around inclusion suggest discovering each individual child through discussion, observation, documentation and discovering how they connect with others and the environment (Ministry of Education, 2014). This document encourages inclusion to be understood as beyond solely an individual approach and includes relational ideas of disability as discussed in the theoretical frameworks section.

\section{Professional Learning}

Professional learning for ECEs may be significant in understanding their positions and practices around inclusion because PD can offer practitioners with opportunities for reflexive practice where they can reflect on their own practices and develop their practices towards inclusion. The Ontario Regulation: Continuous Professional Learning (Early Childhood Educators Act, 2007) requires that each member of the College of Early Childhood Educators should fulfill certain mandated professional development. The requirements involve the completion of an educational course, self-assessments, development, completion, and records of professional learning plans and engagement. Noncompliance with the requirements for continuous professional learning may lead to suspension of the license under the college. To encourage adherence and continuous professional learning, groups such as the Association of Early Childhood Educators Ontario (AECEO) provide access to professional learning activities ranging from single-day workshops to certificates, diplomas, and degrees. At this time, the AECEO has three professional learning modules open for registration and over 30 links to other organizations that offer professional learning and development opportunities for those in the field 
of Early Learning and Care (AECEO, 2019). ECEs' PD involvement is relevant to this study because it is connected to ECE's evolving understandings and practice around inclusion.

According to the College of ECE's Code of Ethics and Standards of Practice (2017), inclusion is "an approach to policies and practice in early years settings where all children and families are accepted and served within a program and where each child and family experiences a sense of belonging and is supported to participate fully in all aspects of the program or service. Inclusive practice includes being attentive to the capabilities, personalities and circumstances of all children and understanding the diversity of development of all children" (College of Early Childhood Educators, 2017, p. 23). Their Code of Ethics also state for ECEs to create inclusive environments where children are able to feel a sense of belonging and inclusion. According to Standard III: Safety, Health and Well-being in the learning environment, ECE's are to access appropriate resources to design the environment to ensure safety and inclusion for all children. This includes incorporating early intervention strategies into the program and direct environment (College of Early Childhood Educators, 2017). This definition of inclusion is significant because it will be later seen again through participants' responses in the interview findings.

\section{Childcare Administration in Ontario}

As stated earlier, childcare currently does not exist within a universal system, and rather runs similar to business model (Friendly \& Prentice, 2009), which are for-profit and depend on consumer fees for service. Thus, administration in each for-profit centre are not only working as supervisors and leaders of the centre, but also as possible marketers for the business service.

Their roles described by participants in this study may reflect that and also play a part in ECEs perspectives around administration. This information is significant to this study because the research questions involve how ECE's perceive administration impacting practices of inclusion. 
As administration is a strong part of each childcare centre, the context in which they exist could be important.

According to more recent events, there are significant impacts as a response to a governing party canceling a $\$ 50$ million fund to aid childcare centres in Ontario. These funds are now expected to arrive from consumers/families enrolling their children in the programs. With increasing fees for families and less funding for childcare providers, there may be impacts on all levels of employees at the centres. Administration structures may be experiencing more pressure for funding distribution and ECEs may be experiencing additional hardships as results of financial tension impacting their quality of practice.

This section highlights the significant areas in the context of ECEC that will be seen and explained throughout the study. The current state of childcare in Ontario, common misconceptions of inclusion, Ontario's definition of inclusion and ECE's expectations and standards of inclusive practices all play a significance and will be visited later in this study.

\section{Theoretical Framework}

In this section I will use theory and discourse around disability to create a framework for the study. Discourse around disability studies, the medical model of disability, the construct of normal, and notions around disabled childhoods will help to theorize the findings of my study. I have used the direction of Disability Studies to guide the entire study.

\section{Disability Studies}

Disabled people are the largest minority group globally and most of us are bound to acquire a disability at some point in our life (Goodley, 2001; Kafer, 2013). Still, there are many untouched ideas that reproduce the traditional notions of how disability and disabled people are perceived. We understand that certain times and spaces are more disabling to some than others 
(Kafer, 2013). For instance, an early childhood setting that has a front entrance with a set of stairs only is disabling to a child using a walker or wheelchair. Or an assessment criteria that expects full sentence speech from a preschooler with specific language impairment (Horowitz, Jansson, Ljungberg, \& Hedenbro, 2005).

The emerging field of disability studies brings the relations between bodies and social space into consciousness (Titchkosky, 2011). For example, the relationship between the child who is understood as "dysregulated" and the space set up with expectations around regulation and behaviour expectations of parents, available resources, etc. The outcome of these relations and the direction they go create a disability for the child that is perceived as behaviour only. Through scholarship and activism, disability studies make those who are interested, attend to and rethink the way we have traditionally perceived disability and disabled people (Titchkosky, 2011). In this study, I aimed to use disability studies to shape my inquiry and analysis. To ask questions that challenge notions around normalcy and perceptions of disability and disabled people as an individualized problem which they must bear and seek intervention for (Michalko, 2002).

\section{Critical Disability Studies}

Critical disability studies have inspired me to explore theory beyond the social model of disability in this study. I have used this direction for the purpose, research question, data analysis, and discussion to challenge the conceptions of normality embedded in society (Goodley, 2013) and specifically, in the field of early childhood education and care.

Rooted in the activism from disabled people in Europe and North America in the 1970s, critical disability studies involve the inquiry by disabled people, starting with the experience of disability but never-ending with it (Reaume, 2014). Critical disability studies examine how 
disability intertwines with race, gender, class, and sexuality, how these intersections influence various power relations in the world, and how this shape the varying experiences of disabled people. Critical disability studies attempt to identify the barriers that preclude disabled people's participation in social life, but more importantly, queries the normative assumptions that underpin our everyday world, including the spaces in which ECEs work.

Through the framework of critical disability studies, I began to understand the aspects of early childhood education and care that pathologize physical, mental, and sensory differences and recognized it as in need of correction (Reaume, 2014), which may be some of the barriers in achieving real inclusion for all children. I also used this framework again when challenging ECEs' narratives that vouched for normative conceptions and suggested implications for practice.

\section{Medical Model}

The medical model of disability is strongly rooted in the clinical diagnosis, rehabilitation, and restitution of a disabled individual (Brisenden, 1986; Fisher \& Goodley, 2007). The disability is seen as a solely biological phenomenon (Fisher \& Goodley, 2007). By extension all the problems faced by disabled people are viewed as flowing from their biological differences. Medical professionals, such as doctors and psychologists, are expected to make sense of the abnormality and create a diagnosis and treatment plan that will work best to restore normality (Fisher \& Goodley, 2007). The opinions of medical 'experts' on disability are rewarded with more recognition and have strong impacts of reproduction through their powerful influence from books, articles, and lectures (Brisenden, 1986). The perception that anything medical is automatically a fact is what keeps this model so dominant (Brisenden, 1986). Additionally, disabled experiences and perspectives are discouraged during the many healthcare processes 
included in early childhood (Fisher \& Goodley, 2007). These "expert facts" (Brisenden, 1986) and lack of inclusion of disabled perspectives (Fisher \& Goodley, 2007) only lead to the objectification of disabled people as inadequate rejects of society.

Disabled People's International (DPI, 1982) defined impairment as "the functional limitation within the individual caused by physical, mental, sensory impairment" and disability as "the loss or limitation of opportunities to take part in the normal life of the community on an equal level with others due to physical and social barriers" (Goodley, 2011, p. 8). The medical model of disability is the most dominant way of understanding disability in therapeutic and educational fields (Shyman, 2016). Comparing these definitions gives an interesting look into how disability is globally perceived and how not considering other reasons for barriers puts disabled people at an ongoing disadvantage since all their challenges are medicalized or viewed as medical by nature.

\section{Construct of Normal}

In the contemporary Western world, disability is generally not a desirable state. It is almost always viewed as something to be prevented, cured, or lived with as a tragedy (Michalko, 2002). Disability is viewed as a departure from normal physical, and by extension, social and culture functioning.

In order to analyze perceptions of disability from ECEs, we must understand construction of normality or the average body. This section will help us theorize the notions around normal and their presence in ECEC. A norm, average, or standard calculates almost every area of our contemporary life (Lennard, 2006). The introduction of the term 'norm' in the English language can be traced back to 1840 as meaning "constituting, conforming to, not deviating or different from, the common type of standard, regular, usual" (Lennard, 2006, p. 3). However, even before 
then, the term had significant social impacts after justified by French statistician Adolphe Quetelet (1796-1847). His definition of a normal man consisted of both a physically average and morally average construction (Lennard, 2006). Following the idea that "an individual who epitomized in himself, at a given time, all the qualities of an average man, would represent at once all the greatness, beauty and goodness of that being" (Lennard, 2006, p. 5). With this ideology, the average or middle man is then thought of as an ideal. This normal body is now used to measure human achievement (Michalko, 2002). Through the research question, "How do ECE's understand inclusion," I inquired about the role 'normal' and notions of normalcy that play in perceptions of inclusion.

\section{Disabled Childhood}

Although there is social science research exploring the lives of disabled children, there is less examination on the interplay of disabled children's experiences and their social settings (Curran \& Runswick-Cole, 2013). Disabled children's childhood studies consider the dominant discourses around disabled children and challenge them with disabled children's real experiences (Curran \& Runswick-Cole, 2014). Similarly, disabled children's childhood studies also challenge the discourses of 'normal' childhoods by placing equal value on every childhood, without solely identifying it through a medical and developmental lens (Curran \& Runswick-Cole, 2014; Hooper, 2013). After the construction of the notion of 'childhood', theories centered around 'child development' were close by. Defining standard stages and expectations for each child (Curran \& Runswick-Cole, 2014). These theories supported by 'science' then created norms around what we view as an ideal child and an ideal childhood. Thus, creating disability for the children not confining to the norms and further being situated as outsiders (Curran \& RunswickCole, 2014). 
As an example, we often use time as a measurement for achievement, alongside development. Such as, a child should be expected to talk between 18 to 3 years of age (Holt, Saltzman, Ho, \& Ulrich, 2007). Expecting this, in this study, I questioned the use of time and other measurements of normal human achievement. How does time and 'standard' development consider disabled children? How do we consider time for children labeled as having delays? Adhering to 'crip' time is more than just allowing extra time to those needing it. It is about flexibility that recognizes that people arrive at different rates or process language at different rates (Kafer, 2013). This understanding was used throughout the project to use time and other measurements when thinking about inclusion.

This section aimed to highlight the major ideas around disability that my study will follow. The concept of body and social spaces, the construct of normalcy, the tensions between time and development and intersectionality are all carried through this thesis.

\section{CHAPTER 2: METHODOLOGY}

Through a qualitative methodology, I had the objective of exploring ECEs perspectives around the research questions. As shown through gaps in recent literature surrounding this topic, the participation of ECEs seemed far less than teachers and qualitative explorations of the experiences of educators in general, whether ECEs or not, also seemed far less especially around administrative practices and their impact on inclusion. Therefore, in this study I invited ECEs' as participants. This section will include a step by step process of how this study had been designed, conducted, and analyzed. 


\section{Research Approach \& Design}

The study has followed a qualitative approach that included one one-on-one in-depth interview with each of the three participants. Details about how this approach was designed will be shared in this section.

\section{Interview Guide}

Objectives for this study were effectively achieved through careful choice of open-ended questions. Answers were provided by the participant rather than myself through predetermined answer criteria (Lewis-Beck, Bryman \& Futing Liao, 2004). Open-ended questions aided during interview procedures as they opened opportunities for ECEs to share their perspectives and narratives.

I created an interview guide consisting of 10 open-ended questions that involved the general areas explored for the purpose of this study (Leavy, 2017) and 18 additional prompts. I used the funnel technique which organizes questions from broad to more specific (Leavy, 2017). I arrived with the final 10 questions after narrowing and refining my original list alongside my supervisor. Some new questions also emerged during the interview process, such as probes requesting further explanations (Leavy, 2017). For example, if I felt that the participants needed to be guided into reflective practice by reflexive questions (Schon, 1983), I would spontaneously ask new open-ended questions that aimed to explore the answer for the previous question more specifically (Lewis-Beck, Bryman \& Futing Liao, 2004). Such as asking, "So what would you say is inclusive about the program planning you mentioned?" This may have lead answers to be directed towards those that confirmed my understanding of potential data and may have inadvertently led participant responses. I will address this in the final chapter of the MRP. 
The interview questions also encouraged narrative. "A narrative can be understood to organize a sequence of events into a whole so that the significance of each event can be understood through its relation to the whole" (Elliott, 2005, p. 3). The guiding questions signaled both chronological narratives and/or those that withheld most meaning in relevance to the question and the participants understanding of the topic. For example, some questions began with, "Can you recall..." and aimed to draft out all possible narratives that resonate with the participant. Using this approach, participants were encouraged to connect events in meaningful ways for the purpose of meeting the interests of the topic and thus offering deep insights about their first-hand experiences.

\section{Revisions to interview guide.}

Initially, the interview guide consisted of open-ended questions that were more directed towards the feelings of participants. Although the objective was to explore the experiences and narratives of the ECEs, after close thought and discussion with my supervisor, it was evident that questions around feelings were distracting us from the main objective and alone may not have gotten us evidence of practice. This would then not allow us to see what is early learning and care for disabled children, which was a goal for this research. Again, forgetting about disability in a study that urges to remember disability. Therefore, revision to the interview guide was made

and questions were remodeled to include prompts of real experiences with inclusion and support instead of just feelings. For example, "how do you feel about your practice of inclusion" was replaced with "What are some examples of how you practice inclusion."

\section{The Role of the Researcher}

Johnson \& Christensen (2017) stated that in-depth interviews can take two varying forms. The first where the relationship between the researcher and participant resembles one of an 
informant and teacher where the researcher aims to learn from their participants. The second occurs when the researcher is also a current or former member of the group being explored. Both these relationships were present during the study as I identified myself as a former practitioner in this field but because I have only been situated in this field for a minimal time and with minimal field experience, I do not claim to be as knowledgeable in in-service understandings as the research participants and rather aimed to learn from their positions.

\section{Sample Selection}

Criteria for inclusion and exclusion played significance to the collection of data. Predetermined criteria required of the potential participants increased the chances of participants offering rich data to the study (Salkind, 2010). Specifically, the study aimed to recruit ECE's who were currently working or had previously obtained full-time employment in an early childhood education and care setting, spoke English, and had experience with disability, and would be available to meet in Toronto for a 2.5 hours long interview.

\section{Full-time employment.}

Full-time employment served importance to this study because a full-time professional in the focused early learning setting may be better guaranteed to have deeper engagement with the themes of the interview when positioned against a potential participant who has not been or is not employed as a full-time practitioner. This study justified this method of purposeful sampling to ensure that the participants with most experience would be contributing collections of richer content by embracing more experiences and understandings.

\section{Experience with disability.}

Experience working with children with disabilities was preferred but was not an aspect determining a potential participant's inclusion or exclusion in the study. This criterion was 
specifically set to add significance during the analysis of research data, as those who had experiences with children with disabilities could have different understandings of inclusion. Because disability is relational, more experience could have impacted their understandings (Thomas, 2004) and their interview responses would have held different meanings from those who did not have such experiences.

\section{Overview of participants.}

The final sample for this study comprised of 3 participants. Raquel, who has temporarily left the field after 2 years to focus on completing her Bachelor's degree in Early Childhood Development. Alex, who has permanently left the field after 7 years of practice, and Zara who is a self-identified registered early childhood educator (RECE) and has been practicing for over 4 years.

\section{Recruitment}

As a MRP, the expectation of this study was to have it designed, conducted, analyzed and written up within a short time frame of 5-6 months. Therefore, I aimed for sample size to be small, consisting of 3 participants. This number of participants were suspected to be enough to gather rich data but also convenient enough to manage my time frame. Due to a small sample size and the anticipation for rich research data, there was crucial attention paid to recruitment so that the recruited participants could offer the most to the study.

This study adopted convenience sampling with all participants and all contacts from preexisting relationships (Frey, 2018). Rather than seeking out participants through alternative sources (social media, in-person, or snowball technique), I used my strong network of friends and colleagues from the field of early childhood education, for recruiting purposes. Once the research proposal received ethics approval from Ryerson's Research Ethics Board, I formally 
introduced the study to my network via email using an official recruitment letter, email statement and letter of consent. These documents included the general topic of the study, what is being asked of the participants, potential benefits and risks, agreement of confidentiality, contact information, and options for consent. Although emails were sent to 10 individuals, 3 were selected for the study after many potential participants stated that they were not able to meet for a 2.5-hour interview at the location. Some were outside of the GTA and some were mothers who could not find childcare that would give them the opportunity to commit the time. Those who were interested in participating in the study or had inquiries contacted me via email and a date and time was set according to their schedule.

\section{Revisions to recruitment strategy.}

In the initial design, I aimed to recruit educators directly from for-profit childcare centres. For-profit childcare centres consist of early learning programs where fees are relied on for operation (Friendly \& Prentice, 2009). This market competition may exacerbate power imbalances within the centre between ECEs and administrators/supervisors, as leadership in a centre may place pressure on front-line staff based on profit motivation. For these reasons, it was initially meaningful for this study to sample educators from for-profit early learning centres, in order to open a window for educators to discuss the possible hierarchy experienced in their professional work settings.

However, it was realized that in order to recruit educators from for-profit centres, the study would have needed support from centres themselves before following through with the recruitment process. Due to time restraints and potentiality of for-profit centres hesitating to welcome a researcher into their centre, I then decided to recruit participants outside of centres. 


\section{Data Collection}

I used one-on-one in-depth interviews to deeply explore the participants' points of views, understandings and experiences (Leavy, 2017). All three interviews were about 1 hour long. Participants were invited to use their own language to direct their responses, including long and detailed answers if they chose. Appropriate prompts were used to direct more detail. For example, as Alex briefly mentioned tensions between ECEs regarding code of ethics, I waited for her to complete her initial response and then prompted her to share more about what those tensions were. Lastly, all open-ended questions directed focus on the research topic such as, "in your own words, how would you describe your attitude towards including children with disabilities into general learning environments?” (Leavy, 2017).

\section{Data Analysis}

The 3 interviews were transcribed verbatim. I then used thematic coding to organize the research data, where I identified major themes in the research findings (Johnson \& Christensen, 2017). This process meant gathering significant data and organizing them into salient themes which were later used for discussing the findings to verify or challenge the existing literature (Silver \& Lewins, 2014). The 3 themes identified were definitions of disability, perceptions of inclusion, and understandings and opinions around administrative practice. I used an inductive approach as I made generalizations and conclusions from the interview data (Johnson \& Christensen, 2017).

\section{Ethical Dimensions of the Research}

Throughout the study, I prioritized practicing ethics. Firstly, participants' autonomy was considered and controlled for prior to conduction. Possible factors harming autonomy included lack of freedom to freely consent to the study due to possible feelings of obligation caused by 
our already existing relationships. I prioritized free, informed, and ongoing consent to participants when introducing the full details of the study, including potential risks. Participants were also made to feel free to withdraw from the interview or entire study at any given time they desired, their freedom of choice in the study was not interfered with in any way and statements explaining that they have no obligation to participant due to our relationship were conveyed in both writing and verbal. Participants were also invited to expand, revise or explain their interview transcripts, however none of the participants decided to.

Secondly, the participants' information; name and the content of their interview were kept confidential, only shared with my research supervisor. All identifying names and titles were changed to pseudonyms during transcriptions and original files of audio-recordings were destroyed immediately after transcription.

\section{CHAPTER 3: FINDINGS}

The data I collected from the interviews suggested 3 themes. Firstly, there are specific ways disability had been defined by the participants. Disability was framed around the individual, as a biomedical issue, a developmental error, and a problem of violence or unpredictability. Next, the findings included how inclusive practice is understood and narrated by the participants. Subthemes followed the physical environment, support, programming, acceptance and creating sameness. Lastly, understandings and opinions around administrative practice in their centres are presented. ECEs spoke around their feelings towards their supervisors, the roles they saw practiced, what they wish for from their administration, and their

own involvement with PD. In this section, I aimed to use passages, quotes and stories from the interview data to present the organized findings. 


\section{Definitions of Disability}

\section{Individual.}

It seemed evident throughout the interviews that disability was understood by participants as within the individual. Although there aren't any quotes explicitly defining disability as an individual problem, all three participants explicitly indicated this when introducing disability through individual children and their apparent impairments. For example, when asked about their examples of inclusive practice, narratives starting with "there was um just one little girl..." "we had a little girl..." "obviously it was really difficult for this one child..." "So, we have this one child in the preschool classroom. His name is Thomas... uh he's diagnosed with Autism..." Impairment and the child as an individual were introduced first. For example, "we had a little girl who had major severe anxiety" and "He's diagnosed with Autism." Individual children were labeled first to refer to stories of inclusion.

Additionally, not only were the children introduced as individuals, their individuality was also closely associated with their impairment. During an interview, Alex stated "you have to consider everyone's individual needs. If they have a special disability, like if they're just like in the proper development, it doesn't matter because everyone's personality is so different." She directly associated disabilities as individual needs. She also stated that every person has ranging individual needs therefore differential experiences faced by disabled children do not matter. With this understanding, it is possible to reproduce the notion of disability as an individual problem while also further classifying disabling experiences as not worthy of open discussion. Later when prompted to share more on this response, she stated that "everyone's so different right, so what will work for one child won't for the other. So, I feel like it wasn't such a huge difference for me, if you know what I mean, because I know everyone has such individual needs.” Again, disability 
is understood as no different than an experience anyone may have. Although it is argued that any person may experience a disability at any point of their life (Goodley, 2001; Kafer, 2013), in this interview Alex seems to be referring to difference that every child has within them and not necessarily difference they experience socially and relationally.

\section{Biomedical issue.}

There were some instances during the interviews in which disability was spoken about as a biomedical issue. ECE's acknowledged the existence of the biomedical understanding of disability through many phrases and statements, including, "We are not doctors but..." That being said, even though they may not be doctors, they implicitly understand disability as a medical problem that can be identified and treated through medicine. They display this understanding when they designate children with medical terms such as "behavioural issues" and "gross motor delay."

In another instance, Raquel seemed to understand the diagnosis of a child as possibly critical to understanding his "red flags." She stated, "we had this child in our program and we $100 \%$ saw red flags and he was not diagnosed because mom just thought that he was perfectly fine..." Implying that the child is in fact not perfectly fine and implying there is an underlying biomedical issue at hand which can be better catered to and treated if diagnosis was done as a first step.

Raquel displays the understanding of disability as a medical program again when she mentions later, "if we feel like there is someone with a red flag we need to tell her (the supervisor), like you need to call in our early interventionist." It would be more interesting to know what Raquel meant by red flags at this moment. Did she mean the violent behaviours she referred to as red flags in other parts of the interview? Was the early interventionist being called 
as a medical expert or as a resource to connect the child and their family with social resources in the community or to connect them in the daycare? The term red flag will be discussed again in the discussions chapter of this MRP.

During the interview with Zara, she stated "Like in the beginning of the year when Thomas came in, we were having a lot of trouble because he wasn't diagnosed then. So, we were still trying to figure it out." She implies that without a label calling attention to the apparent impairment understood as a medical problem, it was difficult to understand the child. She needed a medical diagnosis to understand the child in her care. An issue that she may not have been experiencing with children that are not perceived to have disabilities. In other words, only children that are perceived to have impairments or developmental 'delays' need to seek medical intervention, whereas non-disabled children can be understood in other ways. When prompted to share more on the issue she felt, she stated, "we needed to know more and it's hard because he's not verbal." She presented the understanding that verbal communication was the ideal form of understanding any child and without this, she required medical help.

\section{Developmental error.}

Disability has been classified as a developmental error during many points of the interviews. Disabled children are discussed as separate from their 'typically' developing peers and their impairment is highlighted in this context by talking about their 'irregular' or 'unusual' development. There is a developmental framing of disability. For example, the definition of disability as a developmental error is raised when participants in the interviews spoke about “typical development", "normal," "proper development" meeting "developmental goals," and “developmental delays." This language was commonly used when participants were talking about disability, disabled children, and inclusion. 
Similarly, Alex shared a story about a young girl, in which she stated, "so most of the children were 18 months at that point and she was also 18 months but she had a disability where she couldn't walk yet her legs weren't developing, her gross motor skills weren't developing as, you know, in the normal range. she had a delay." The mention of age followed by a "but" introduces the idea that standard development exists but the child is experiencing a developmental error acting as a barrier to her age appropriate development. Additionally, the child's non-normative development is explicitly categorized as a delay by pinning it in comparison to a normal range of development. She makes reference to this understanding again when she mentioned "proper development" in a later part of the interview.

In her interview, Zara talked about how the typically developing children in her care react towards their disabled peers, she stated, "they physically see it too like... that he's learning all of this... Like he's not able to do... all the things they're able to do. A lot of them have younger siblings as well so they probably see him more as a younger sibling." By stating this, she implies that disabled children in the room are lower in the development latter as they are perceived to behave similar to the non-disabled children's younger siblings. Development is used as a point of chronological comparison.

In another instance, Alex used the word 'wrong' to describe the perceived impairment of a child who was not walking at 18 months old. She stated, "because her legs um, they were... I don't remember exactly what was wrong." According to Alex, her disability was the 'wrong' in her because it was not following a normative standard of Western child development.

\section{A problem of violence.}

In other instances, ECEs sometimes defined disability as violent, out of control and in need of taming. Disabled children were occasionally implied as unpredictable deviants in need of 
constant surveillance for the sake of not only their own safety, but also for the safety of others. Raquel shared a narrative about a child sharing interactions with a peer that he knew from the school and his Korean community. She stated, "if you didn't watch him for even like 5 minutes, he would go in and attack other children and there were so many times where, I mean the staff was watching him but you know, even if you like quickly go in to help someone use the washroom or whatever, you know, you turn your background to just speak to a parent quickly or whatever... he would like attack this one little girl specifically." His interactions with a familiar peer were understood as violent attacks and constant observation of the child was not even enough to ensure his and others' safety. When describing this specific child, Raquel also mentioned that he was not formally diagnosed but instances and behaviours such as the ones described in the story were reasons why ECEs believed that he needed a formal diagnosis. This neatly described his perceived violence and unpredictability as the sole characteristics of his disability. His disability was seen as a problem of unpredictable violence.

When talking about including this child in the program, Raquel stated that she preferred the help of an extra supply staff that would keep by the child's side during all times of the day to manage his behaviours. She stated, "he would always run out of the classroom and like nap time was just like, he couldn't even sit there... he's running off into the hallways... running off the playground. So that way during nap time or you know, when the children are resting he is not disrupting other children." His behaviours implied as unpredictable were perceived to be in need of constant hovering by an adult to keep him most confined.

Similarly, there was a point in Alex's interview where she did not explicitly describe disability through negative characteristics, but used the word "behaviour" as a possible mask to get the meaning across. When speaking of some disabled children she cared for in the past, she 
stated, "I had a couple, let me think...I had with behavioural when they were in the toddler room.... And yeah you could just tell like from off the bat that they were um... they had lots of energy..." When heard orally, there was almost an obvious meaning assigned to the word energy. Almost sarcastically when paired with the previous adjective "behaviour." Behaviour was not described as a neutral noun and neither was energy. And once again, both terms were used as the core definitions to describe the disabled children.

Finally, Alex also implied a child's disability was their negative attribute. When sharing a story about a new child entering the program whom she had never met before, she claimed that ignoring conversation about disability would best allow her to include the child in her program. She stated, "I would just view them like everyone else, because if I go into like um, a mentality where I think too much about "oh they have this or they have this" and I kind of like highlight it, I feel like it would just, it would kind of almost like...um, I don't know how to say it... it would just add fire to the fuel, you know what I mean? It would be having me thinking in an almost maybe possibly negative way." According to this definition, disability is seen as a burning fire and noticing it in a child will only add fuel to it. Disability seemed to be understood as a negative attribute better to be ignored in order to promote inclusion of that child.

\section{Understandings of Inclusion}

Another major theme in the findings was around how inclusion was understood and narrated. According to the participants, inclusion involved sameness, acceptance, professional support, programming, physical space and resources. The following section is laid out to present data found for each subtheme. 


\section{Sameness.}

Sameness amongst all children was implied as a successful outcome of inclusion when participants were asked to share stories of their inclusive practice. When sharing a story about a child who had dietary restrictions, Raquel explained that allowing his parents to bring in a different snack allowed him to follow the routine like everyone else. She stated, "so that for snack time he is not sitting and not eating anything... he has something to eat and he is still sitting at the round table with everybody else." She may also be implying that the child was able to have opportunities to create relationships and socialize during this snack time. However, when read literally, the desired outcome is that the child will sit and have a snack like everyone else.

Raquel shared another story of successful inclusion where a child labeled with severe separation anxiety started the program and the ECEs worked with her over a period of time, using different strategies to get her to stop exhibiting the behaviours she was showing in the beginning of her enrollment. By using stickers, calls to mom, visits to mom, and toys of her interest, Raquel stated that "she was busy and had a good time being at the school and ensuring that because we understood she had such severe separation anxiety, we did not want it to be so dramatic, so we made sure to slowly kind of make sure that mom was there she was slowly out of the picture eventually, where she slowly from a day to like an hour, to being in the parent room so like trying to cut that down and eventually it worked out." This example of inclusion seems to be a form of psychological intervention and anxiety management consisting of strategies that allow the child to attend school without her mother. In the same way as everyone else.

In her interview, Alex stated that creating sameness was beneficial for both disabled and non-disabled children because eliminating their difference also eliminates their weaknesses. She 
shares a story about a child taking a longer time to put on his winter gear for the playground. She stated, "the other children are waiting for me and they're kind of like "what is going on, it's taking so long because of this child" You know what I mean? They feel it too, so once we took that away and kind of went with a slower pace and not going by the schedule, everyone was calmer. They actually connected with the child more.” According to this understanding, connections and positive relationships between the disabled and non-disabled can exist once we eliminate differences and find ways to hide disability.

\section{Acceptance.}

In all three interviews, ECEs spoke about acceptance of the disabled child and all children when asked about their understanding on inclusion. Alex said, inclusion to her is “including all people, all children, all families, whoever were connecting with in the setting. Um you know, all staff of all I guess, different ethnicities, of all different individuals with different needs, special needs, children with disabilities like anybody and accepting them." Similarly, Alex stated that an inclusive environment where "they (the children) can do things and feel good about it and feel accepted in the room with themselves and their peers and with the teachers too."

Other conversation was around feelings of belonging and comfort for the disabled child. Zara stated that an inclusive environment needs to be somewhere "where we give every single person an opportunity to be themselves and to express themselves and to feel comfortable in the environment." She added, "everyone that's working together in a classroom feels like they belong. Um... that everyone feels like they are part of the group... Um... what it means as an educator to me is that I'm adapting to children's needs and supports so I can further support them and make them feel comfortable in the day to day program." So, inclusion in this perception means accepting the child but also arranging the environment to support their needs. 
Additionally, she describes the understanding of accepting the child but accepting them as individuals.

To Zara, inclusion also meant for the disabled child to physically belong with the rest of their peers. She stated that assisting the child alone during transitions was not inclusion and that he needed to be part of the group. She stated, "Taking him one-on-one was working ...But it wasn't inclusive. It was him being away from the class. That's not something we wanted. That's something he needs to learn and it's gonna be part of his life...it was the easy way out." Inclusion described as physically belonging to the rest of the group is defined as something the child must learn. Therefore, inclusion is understood as something that is teachable. Something that ECEs teach.

\section{Support \& relationship.}

All three ECEs spoke about inclusion involving support to better understand disabled children. It seems that disability was largely understood as an individual, medical, and developmental problem, therefore, ECEs often associated inclusion with specialized professional support to fix the child or attend to the child's individual impairment. For example, Raquel stated she desired more knowledge on how to work with children with disabilities, she stated, "I feel like it would be supportive of that so we know what tools and activities to be implemented for these types of children. I feel like not until I went back to finish my bachelor's, I didn't learn about... like the weighted blanket..." Raquel insisted on specialized training and supports. Interestingly, these supports have a biomedical understanding of disability. She also identifies children with disabilities as separate from the typical children in her care and understands that different knowledge if needed to work with them. She presents this understanding when she refers to disabled children as "these types of children." Which seems to align with her own 
understanding of disability presented previously in the beginning of the findings section. Raquel also shared her desire to have staff specialized in working with children who were hard of hearing, have speech impairments, and so on. She stated that this would create a more inclusive environment.

In addition to specialized education, ECEs spoke about consistency and one participant, Alex, touched upon relational aspects of disability in order to facilitate inclusion which I will share towards the end of this section. Raquel shared that inclusion was better practiced when staff was consistent. According to her, "because that staff now knows the routine, that child, the behavior of that child..." So, it also seems that experiential knowledge on the behaviour of the disabled child is beneficial to inclusion. Zara agrees to this claim as she also stated that, "It's hard for us to communicate to the new staff each day about what strategies we're using or they won't know what's going on with Thomas." When speaking about what she learned around inclusion from a PD seminar, Alex stated that, "each situation with inclusivity is so different and it can vary from person to person/ child to child... no matter how many times you can get the information, get the support and resources, it's about that experience in itself." Alex implies that inclusion is more than getting specialized resources that understand disabled children through a medical framing. She argued that you must have experience with the child and understand them through the experience. She seemed to have touched upon relational aspects of disability here.

\section{Programming.}

ECEs attested that programming at their centre and in their individual classrooms was one of the main ways that inclusion was practiced. Raquel shared that her programming is planned around the interests of the child to ensure that he/she has something to do during all parts of the day. For example, she stated, "like free play, he loved the water table we would 
always make sure to have the water table accessible on the days he is there that way he can keep himself busy and you know into an activity rather than just running around and being disruptive." This passage presents reasoning behind why programming is done around the child's interests, it is so that child can refrain from behaviours that are understood as negative and disruptive. So that he can be encouraged to stay in one area of the playground as much as possible and not run around.

Contrary to Raquel, Alex seemed to encourage movement when planning her programming. When speaking of a child that liked to keep moving during play, she stated, "they weren't staying at like 1 activity for too long. So, knowing that, not expecting that of that child and kind of setting up smaller activities or lots of activities so that they could jump from one to one to one..." Inclusion for Alex in this scenario meant to not hold normative expectations of any child and rather cater programming to what better fits the child's movement. However, in another part of the interview when Alex was asked to share a story of when inclusion was not working, she shared a story of when more space was opened for a child who constantly moved. She stated, "I feel like we tried it and we needed a lot more support it wasn't just about space at that point for that child... after a while opening up the space, it never helped like it just, they ended up running to another space and another space so that didn't work." Interestingly, the child's movement was accommodated for but with the underlying desire that the accommodation would make them behave less like they were behaving. Space was opened for a running child so that he could stop running. And when he did not stop, inclusion was classified as not working.

In another interview, Zara stated that her programming is inclusive because, "There's no right or wrong. So, it's very open ended, so it's not like this is what we're doing and this is how it has to look or how it has to be done. Like it's very open ended in terms of yeah, we'll give 
them materials or we'll tell them what we're focusing on but how they do it, why they do it, the way they do it is all open ended and it's all open to them to do it their own way." Zara understands inclusion through celebrating the diverse process of learning rather than the desired normative outcome. Additionally, when prompted to share more, she stated, "We don't set limits to anyone, we support them in terms of like, Thomas has trouble with fine motor skills but we won't stop him from doing fine motor activities we'll help him one-on-one like we'll hold the scissors with him so he can do it, we won't be like "no no no, don't use those scissors Thomas, you don't know how to use it, because that's stopping him from learning." For Zara, the process of learning is not expected to follow the norm and it is supported with teacher assistance if needed.

\section{Physical set up and resources.}

The physical set up of the environment and the resources within it were spoken about when asked about inclusion. The participants explained that inclusion is about seeing yourself in the room and being able to follow the classroom routine. Such as "posters, books and toys that are accessible to them and that they can relate to..." or "action figures with people in wheelchairs." However, Raquel stated that these artifacts in the room were not enough to make it inclusive. She stated, “Just because you posted a picture of someone using braille, yet you don't even have a book in the classroom that had braille on it." She stated that a poster representing the use of braille was not enough to give reading access to children who actually used braille. Alex gave an example of an effective resource (sitting cushion) in the classroom that helped a child sit

on the carpet during moments of the day. She said this resource encouraged inclusion of the child because "you could see she was always happy whenever she got dropped off she was excited to come into the room or excited to be in the centre and connecting with her friends." With this 
story, inclusion meant whatever that can allow for a child to follow the routine while also being happy to be in the environment.

Inclusion to Raquel was also about children being able to follow the classroom routine, she shared that using a "visual schedule for some children so they know what's next" was beneficial in including them. Zara also mentioned the use of visual schedules to encourage children to follow the routine. For example, "for lunch the picture is our lunch table in the classroom with children sitting and eating lunch. So, he knows ok it's lunch time, I'm gonna sit on the table. So that has helped." For other children, hiring an extra staff to assist them in following the classroom routine was stated to be beneficial in inclusion as well.

\section{Administration}

In this section I presented the findings on what ECEs spoke on administrative practice around disability and inclusion. ECEs spoke around their perspectives around support from their administration and towards their supervisors, the roles they saw administration practicing, what they wished for from their administration, and their own involvement with PD. The findings are presented in this section.

\section{Support.}

ECEs stated that they had experiences of both being supported and unsupported by administration. Raquel stated that her supervisor would take the initiative to hire extra staff for children who were believed to benefit from one-to-one assistance. For example, she stated, "we have beach day and we can't deal with so and so running around and we need a supply.” Alex and Zara shared similar stories. Alex shared that her supervisor would also make sure to hire extra childcare staff for children who were perceived to benefit from it. Additionally, Zara stated that her supervisor does some research and shares it with the ECEs to support them in 
brainstorming strategies for inclusive practice. This research was claimed to be around inclusion and strategies on working with children with Autism. Zara also stated that she finds her supervisors to be supportive because their office doors are always open. Her and her coworkers access to them during stressful times makes her feel supported. She stated, "you can go there and be like "omg I'm just having so much trouble I just have no idea like what I'm doing, nothing's working" and they really help you in terms of reflecting so you can sit down there and they help you break it down like "what's going on, why do you feel like that?" Having access to opportunities for reflection on her practice was beneficial for Zara in practicing inclusion.

Raquel and Alex stated that sometimes they felt less supported when their supervisors were not able to provide them with consistent extra staff (e.g the same staff) to work with the children who they believed needed one-on-one direction throughout the day. This would then impact their practice with children. Raquel stated, "if she is not supporting the ECEs, it's hard for us to support the children, right?"

Lastly, Zara also stated that she feels her relationship with her supervisor may have been tainted due to the way she felt that she was treated as an ECE. When sharing a story about experiencing a medical emergency, she stated, "I think I would say "feel better" to a stranger if they told me they're sick. But I never like get that treatment from them. It's more like 'ugh ok well I don't know who's gonna cover for you' you know like comments like that make you feel like ok you don't care about my general well-being or like care of me as a human being, you just care for me as a person who's there to meet ratio." She later explained that this weak relationship was one of the reasons she refrained from seeking assistance from her supervisors during stressful situations. Her issues with administration seemed to consist of labour relations and not 
being able to claim sick times, which she claims to impact her practises of inclusion because her tainted relationship holds her back from reaching out for support and assistance. When sharing

\section{Roles of the administration.}

When I asked ECEs to share what they usually observed their administration doing at the centre, the findings were common. Supervisors' main roles in the centre seemed to be centre upkeep and sharing their expertise with the ECE staff. Regular admin tasks required office management, payroll, enrollment, registration, ratio management, calling supplies if needed, and upkeep with ministry and city criteria around the centre including rooms and playground. Findings around their role of sharing their expertise are presented in the following section.

\section{Administrative expertise.}

Administration was also described to share their expertise in situations. Raquel stated, "she had been in the field for so long, she had so much experience where she knew what to do for specific situations." ECEs said they often looked to supervisors to assist them during tough situations. For example, Raquel spoke about her supervisor holding private seminars during meetings where ECEs could share their issues and the supervisor would assist with their expertise. She stated, "we would kind of sit down and talk about the issues in the classroom. For example, I'm sitting down, I'm like 'Jonathan, I see red flags I need help with Jonathan, he keeps doing this in circle time' and my supervisor would say, specifically for this child, 'why don't you try so and so.' And then the next co-worker would be like 'Marvin is doing this and that and I need this...' And then our supervisor would be like 'why don't you try this this and that." Supervisors' expertise was stated to be appreciated, however, sometimes they were not wished 
for. I will explain this next as I discuss what ECEs wished that their administration did and did not do.

\section{Professional development.}

When I asked the ECEs what types of PD they were involved in, the answers varied. Alex stated that her supervisor gave her and the other ECEs articles on a weekly basis to read. Additionally, "She would every two months or so bring us books that you would ask us to read, about inclusion as well." She also claimed to attend 2 workshops during her paid time. Zara stated that her PD involved the articles and Ted Talks that the administration at her centre sent out to staff via email. She stated that although most of the content were things she already knew, it was a good review. Lastly, Raquel did not recall being involved in formal PD but spoke about private seminars her supervisor held that specifically targeted the concerns of the staff in the centre.

\section{Perspectives of ECE's towards administration.}

ECEs expressed varying feelings in response to their relationships with administration. Zara stated that she found her supervisor to be "moody" and that "if you catch her on a bad day, you are.... You're not gonna get what you wanted." Alex explained that sometimes she feels misunderstood by her supervisor and she does not have enough time to explain herself or her side of the situation when she is asked about it in the middle of a busy toddler room. As a result, her relationship may feel tainted. Zara explains that her weak relationship with her supervisors could be because they spend most of their time in the office and rarely view the staff or the rooms in the program. She continued to say, "even if you do go and ask for something like they are not going to really know why you really need it or um... the extent of why you need it because they are not involved as much." Interestingly, this contradicts ECEs stories of receiving expert advice 
from their supervisors. Zara seemed to have claimed that her supervisors have many years of knowledge and are able to provide strategies to cope with stress but also had expectations for administration to be involved more in the program.

\section{What they seek.}

When I asked ECEs if there were some specific changes that they would wish for in regard to administration, almost all pointed towards PD. I could have been because this question came directly after the one regarding their PD involvement. Nevertheless, ECE's desired administration to take more responsibility around PD and provide their staff with better access and accommodations. Zara stated, "I wish she would do more research on her end or provide us with time to go to workshops. Like she's always like "oh if you wanna go to workshops, feel free we'll fund it duh duh duh" but we have to go on our own time... We're not getting paid to actually be there... so it's really hard like we have our own personal lives... we're there for long amount of hours and most of these workshops are at 9pm in the evening." Zara wished for paid PD opportunities that better fit with her busy schedule as an ECE. Alex also desired more seminar style PD opportunities, she stated, "It was more of an experience, and with that experience I feel like learning is stronger and it sticks with you more, do you know what I mean? If we could have it a bit more often."

When speaking of PD, Alex desired that the supervisor would follow up with all the staff regarding the PD they received. She stated, "having a catch up... or like a reflection or some sort of meeting after like 'ok how did you do this?' You know what I mean, call to action after, couple months later because if not, the things you're doing you might just forget about it." Lastly, as for Raquel, she desired more specialized education that she thought would better prepare her to work with children with disabilities. She stated, "I feel like we're more used to 
working with children who are typically developing and etc. So, I feel like having workshops to kinda... that are like, you know, informative of how to work with children with different types of disabilities right? so I feel like it would be supportive of that so we know what tools and activities to be implemented for these types of children."

Lastly, Raquel expressed that she wished that the decision making in her centre would involve the voices of ECEs as well. For example, when speaking of a child who was expelled by the supervisor for exhibiting a source of communication that was perceived as dangerous and violent by the ECEs and supervisors, Raquel stated that she wished her supervisor would have discussed the concern with other staff before taking an executive decision on the matter. She stated, "I feel like it's not helping him and it's not helping the mom." She also expressed the idea that this decision was made by the supervisor due to the influence of the surrounding community that preferred the exclusion of disability and what was perceived as violent behaviour. She stated, "I feel like my supervisor should have gotten that help and support for that family rather than just cover it up just for an image for the rest of the Korean families in the school. To be like “"oh yeah that little family is gone."

\section{CHAPTER 4: DISCUSSION}

The primary purpose of this research study was to explore how ECEs understand and practice inclusion and how they see administrators impacting their said understanding and practice. Through the findings section, I was able to demonstrate the 3 participants' interview data and organize it to promote a better display of the research questions and answers. In this section, I will aim to discuss the findings using literature in this area of study as well as my theoretical orientation to discuss the research findings and what they possibly mean. The main discussion topics will include ECEs understanding of inclusion, a question of who is benefitting 
from this perception of inclusion, and what ECEs desire from their administrators. I will also include the implications for educators using autoethnography data from Fredrick's (2013) research.

\section{Understanding Inclusion}

According to the interview data presented in the findings section, the term inclusion was understood in a variety of ways. It was sometimes understood simply as the integration of disabled children into a general childcare program or classroom. At other times, it was understood as the use of special education within the general childcare program specifically for children with disabilities. And sometimes, it was portrayed as the understanding that the environment is to be responsive to each child and accommodating of their individual needs. In this section, I will refer to how the educators spoke about inclusion and how their definition aligned or did not align with definitions of inclusions from a disability studies standpoint. I will also provide a scholarly discussion on the differences between integration and inclusion and use theory to discuss why educators might be using the term inclusion as interchangeably with other terms.

Although the participants sometimes described inclusion as the integration of disabled children, there is, in fact, a significant difference between the two terms (Harman, 2014). According to Harman's (2014) reasoning, a program is simply integration if those involved in it speak about adding extra adaptations or services to help the child fit in. Integration models assume that there is something wrong that needs to be corrected in the child. Therefore, the adaptions made to the child are attempts to help the child better fit into the general classroom. On the other hand, if a program is inclusive, those involved will speak on helping everyone and the classroom or program will be changed to promise the success of all children (Harman, 2014). 
Therefore, models of inclusion do not believe that any child should be changed but rather the environment and systems and relations within it must be enabled to change in order to include children (Harman, 2014).

After understanding the difference between integration and inclusion, we can begin to discuss why educators explained inclusion the way they did. The participants in this study sometimes perceived inclusion as integration (adaptations in the child to prepare them to better fit the program) because they understood disability as an individual and medical problem. Therefore, this position also framed their perceived "inclusive" practice and understandings around inclusion. Thinking back from a disability point of view, this lens sees inclusion as the relation between bodies and social spaces (Titchkosky, 2011). Inclusion would then consider individual bodies, but not alone. The social spaces existing with the bodies are optimal for consideration. Meanwhile, integration is then better framed through a medical lens that encourages the modification of individual beings either through direct medicine or medically centered resources (Fisher \& Goodley, 2007).

\section{What Participants Seek from Administrators}

In this section, I will try to make sense of why educators expressed to want specific resources from their administrators. They mainly presented the desire for more one-on-one staff to work with disabled children or designated children as well as more or any specialized education as a part of their PD opportunities as employees.

I asked myself, why did my participants desire these specific outcomes from their administrators? It could be because of their views and understandings of what disability and inclusion are. This could have influenced them to believe that because disability is a medical problem and inclusion means the placement of disabled children into a general classroom with 
special supports, then asking for one-on-one support and specialized education is surely the key to successful inclusion.

I should also note that ECEs seemed to have an understanding that the administration has a high influence on how the centre understands and practices inclusion and hold systemic significance as leaders of the centre. Although disability was largely referred to as an individual and medical concern, participants did confront the relational aspects of disability by calling out the fact that lack of administrative support and understanding impacts disability and creates more disabling experiences for children in their care.

Some literature also claims that there is significance of leadership, such as administration, on inclusive practice in early learning and care settings. According to Ruairc, Ottesen, and Precey (2013), leadership in schools is significant because schools are commonplace in a society in which formal teaching and learning take place. Therefore, the role of leadership in any school or program where learning takes place is powerful and should not be undermined.

Ruairc, Ottesen, and Precey (2013) explain that the array of understandings, meanings, beliefs, and values adopted by the leadership of a program are influenced by the larger social environment in which they exist. For example, Raquel's supervisor's decision to expel a child from the program was influenced by the larger community's preference for the exclusion of disability and 'danger'. Raquel also understood this systemic impact as she expressed that her supervisor's decision to expel the child was influenced by what the surrounding community would have wanted. As mentioned in the findings, "I feel like my supervisor should have gotten that help and support for that family rather than just cover it up just for an image for the rest of the Korean families in the school. To be like " "oh ya that little family is gone." The role of the leader at Raquel's centre was critical here. It was powerful in framing and defining the meaning 
of disability (Ruairc, Ottesen, \& Precey, 2013). But we must also realize that if the larger discourse outside the immediate walls of any early year's centre frames leadership, then any change within a centre is also dependent on the larger change in the dominant society.

In the findings of the interview data, I discovered that ECEs quite often looked to their supervisors and administrative teams for practice-related inquiries or stresses. For example, Zara stated that she and her coworkers are welcome to reach out to their supervisors with daily concerns or stressful situations and their supervisors provided solutions or recommendations using their higher level of experiences in the field of ECE. As well, Raquel's supervisors would hold small seminars where ECEs can express and explain the issues they are having and the administration team would help resolve them. From these findings, we can clearly understand that leaders in every early childcare setting in the study were influential to the practice that exist within them. Aligning with the literature that agrees that administration and/or leadership have critical and powerful roles in practice and understanding (Lehr, 1999; Marvin, LaCost, Grady \& Mooney, 2003; Ruaric, Ottesen, \& Precey, 2013).

According to Ruaric, Ottesen, and Precey (2013), we should not be undermining the role of the leaders in programs and schools. Instead, greater participation and democracy is more likely to strengthen the system. However, what does greater participation and democracy in the centre look like? And how does this take place in centres where we can suspect unequal power relations or tensions between the administration and front-line ECEs? According to Ruaric, Ottesen, and Precey (2013), Raquel's supervisor should not have made the executive decision to expel a child who was exhibiting perceived 'violent' behaviours but instead should have practiced democracy to arrive at a decision. I wonder who should have been included in this democratic decision-making process? Just ECE's or the child, their family, and the community 
as well? Unfortunately, this isn't something the authors included in their discussion but should be something considered further as an implication for leaders in early childcare centres.

\section{What is Inclusion and Who is Benefitting?}

According to the findings, ECEs shared common ways of describing their stories and understandings of inclusion. Inclusion meant who was existing in the environment, the physical set up of the environment and the resources within it, the relationships in the environment, the support, and the programming. Many that seem to be suggesting benefits for disabled children. However, after hearing and attempting to analyze the understandings of disability through the perceptions of inclusion, I am tempted to ask, who is truly benefitting from these exercises? Are disabled children and children in general always benefitting? Or are these specific perceptions of inclusion a mask over what is actually the practice of integration, confinement, and cure to make it seem more welcoming and up to date with relevant government documents? In this section, I aim to discuss the data that prompts me to point out the concerns of these specific perceptions of inclusion described in the findings.

When ECEs describe their stories of inclusion, we can get a sense of who benefits and what the desired outcome is. When sharing a story of a boy who was in perceived need of intervention and the struggle to receive parents' consent, there is this implication that inclusion means labeling. Not only that, inclusion means that parents must adhere to viewing their child the way the teachers view him and the way that society prefers to view him. If they do not, "inclusion" becomes difficult to achieve. But why is that? As previously discussed in the context section, identification needs to happen in order for families and educators to advocate funding for resources. The resources are not already present. This explains why labeling might seem like an answer. 
Returning back to the story, because it may have been nearly impossible to apply for funding without a label, the centre in this specific story hired an extra childcare staff from a supply agency to assist the child throughout the day. Inclusion in this aspect meant "he got that one to one, that way he is not running off into the hallways... the playground... when the children are resting he is not disrupting other children because someone's sitting right next to him...or like snack time, for example, someone would kind of just sit right beside him or behind him to ensure he doesn't get up and run away, so things like that." Now, I return back to my question, who is benefitting from this definition of inclusion? Is it the child who is being confined to follow the normative routine and behaviours or the educator who is expected to mold the child to become an ideal citizen ready to perform in an orderly fashion?

Similarly, talk of confinement and cure were common when sharing their stories of inclusion. In another story where a child was observed to enjoy running, their space was opened up as a perceived strategy for inclusion. However, the expectation was for the child's running to stop as a result of more open space. The child was not wanted for running but rather wanted to be seen participating at learning centres like their peers. The end desire of inclusion was again confinement and when this was not achieved, the ECEs realized they needed specialized intervention because their perception of inclusion was not working.

In this section, I will also discuss what "types" of disabled children seemed to benefit from inclusion and why. According to the stories from the participants, their perception of inclusion worked when the child was presented as a passive person who was more easily accepting of adult instruction and how the adult wanted to accommodate for that child. For example, Raquel explained a story of when a child who was described to have severe anxiety came into the program. The ECEs placed various strategies to ensure the participation of the 
child. In this case, their perception of inclusion worked. But what if this child was active and also ran around a lot or was constantly on the move? Would inclusion still work? I also wonder what was the difference between this story and the story of the active child who kept "running away." Recalling from Huang and Diamond's (2009) study that was reviewed earlier, participants were less in favour of inclusion when the child exhibited behavioural disability. Using this finding to explain the findings of this study, it seems that inclusion was more favoured for children perceived as passive and less preferred for children who were perceived as active.

This leads me to discuss the concept of controlling movement as this seems to be directly connected to the findings. In her work, Fredredick (2013) explains how many teacher's classroom management strategies aim to direct the student body. Similar seemed to be the case in my participants' stories as they used various techniques to control what a child did with their body, such as running or getting up from a table, or getting up from their napping mat. For example, Raquel explained how her centre used one-on-one adult support to direct a child's body. Zara and Alex altered the environment in aims to direct a child's body either through opening up spaces in hopes of his running to stop or directing peers to hold the child's hand through transitions. Regardless of the method, there seemed to be a need for managing movement. Especially for those children who are perceived as outside of typical developed. Frederick's (2013) use of Foucault's (1987) ideas on hierarchy might explain this as an issue of power between teacher and child. However, Reaume (2014) would also argue that this is an aspect of early childhood education and care that pathologize physical, mental, and sensory differences and actively seeks to correct it. Therefore, because the children described in the participants' stories exhibited active movement that was seen as chaotic, disruptive and atypical, there seemed to be a constant need for correcting or altering this movement. Passive children 
seemed to be easier to direct while active children were deemed difficult and in need of further intervention. Their higher movement activity was considered a risk coming in between their success as a learner.

So, what does this mean for disabled children? I will use Kafer's (2013) ideas around time and disability to explain disabled children's potential experiences. Kafer (2013) argues that certain settings impact disability and may cause disabling experiences for some more than others. Can early childhood education and care be a disabling setting when the above perceptions of inclusion are in practice? According to the research findings, Kafer (2013) might argue that these settings are indeed causing more disabling experiences. For example, when Alex who used normative measurements of development to label a child as slow to develop. There was also a story when Alex explained that other children are aware of some children moving "slower" than the rest and the barrier this causes to their social interactions with those children. According to Alex's story, the class followed a timely schedule and crip time: a flexible standard for punctuality or the idea that some people need extra time to overcome barriers (Kafer, 2013), was not practiced or considered.

Lastly, in this section I return back to the term "red flag" that was used by one participant multiple times during her stories. This term was largely used when indicating children that seem to pop out or exhibit behaviours that are perceived to be a warning sign. According to teaching tips designed to aid medical students in learning child development and disability, the term red flag is used to identify developmental delays (McDonald, 2018). "Red flags denote features that indicate further enquiry or investigation is required" (McDonald, 2018, 136). In Raquel's story, the child's "red flags" were similarly used as a reason to inquire further and arrive at a diagnosis. In another area, McDonald (2018) used the term red flag as associating with features of Autism. 
McDonald (2018) also identified a list of red flags of child development, including regression at any age and self-injury such as banging their head after age 2. It seems that this institutional discourse has influence on early childhood education and care settings as ECEs such as Raquel also used such terms when referring to child development and disability.

\section{CHAPTER 5: IMPLICATIONS AND LIMITATIONS}

After discussion, I argue for a need to introduce educators to theories that go beyond the individual and sociocultural approaches of disability. As explained in the sections above, understandings of disability shaped understandings and practices of inclusion which also shaped ECEs desires of administrative support. A shift in understanding of disability through a disability studies and critical disability studies lens could influence a major change in how inclusion is practiced.

I argue for the need of ECEs to gain more PD that would involve less specialized education and more reflection on their own practice and their relations with children. If we understand that disability is relational then ECEs are in a position where they can be active influencers in the relations between body and spaces. Furthermore, as we realize the impact of administration and leadership in early years centres, a shift in understanding of ECEs would lead to a shift in leadership for the future as leaders of the future are ECEs of the present.

Narratives from autoethnographies of educators can be helpful in seeing the impact that a shift in thinking can cause. Frederick (2013) uses a story from her practice as a teacher to compare and discuss the concept of self-regulation through both individualist and relational perspectives. The dominant discourse around self-regulation exclusively focuses on the individual self and implies that the emergence of the self is an individual process. She argues that a less individual-centered approach to self-regulation and a more responsive approach is 
beneficial in her experience. For example, she shares a story of Stevie who seemed to exhibit behaviours similar to the little boy in Raquel's story. He chased friends, enjoyed running often, and hit other friends in a playful manner when excited. Frederick (2013) explained how she teaches Stevie some individual techniques for regulating his own behaviours but also teaches his peers some techniques to regulate their behaviours which will accommodate Stevie's needs. She states, "such as by sitting down immediately if Stevie starts chasing them, to freeze and say 'stop,' or to move closer to a teacher as opposed to laughing, screaming, or running faster" (Frederick, 2013, p.74). As an educator, she makes alterations to the environment and relations in the environment to include Stevie.

Although Frederick (2013) does not connect this story to the term inclusion, this narrative is an example of how her practice actively challenged the normative understanding that selfregulation is solely an individual process. She rather practiced inclusion by altering the environment to accommodate Stevie's needs. I urge ECE's to adopt similar understandings where they can find themselves able to balance models of individual processes and relational aspects of disability in order to make inclusive practice more possible.

\section{Limitations}

When designing, conducting and writing this study, I had many opportunities to reflect on my research design and process. Regardless, as each section unfolded, as a researcher, I became aware of some limitations of this study. The first limitation noticed was during the recruiting period. It became quickly apparent that the guidelines for the inclusion criteria as well as interview details were not accessible or accommodating to the ECEs interested in the study. When designing the study, I was focused on an inclusion criteria that would provide the richest data. Assuming that full-time ECEs with many years of experience in the field would be this 
study's best interest. However, I did not consider the average full-time ECE's work hours when requiring them to meet for 2.5 hours in a downtown location. The combination of an 8-hour shift ending at $6 \mathrm{pm}$, downtown Toronto traffic navigation, and an over 2-hour interview, even very interested ECEs could not commit. As a result, $2 / 3$ participants included in the study were not current ECEs.

Consistent with qualitative research designs at the pilot or exploratory stage. This sample size is small and does not reflect the perceptions of all ECEs. Additionally, participants experience in the field was less than 7 years, it can be argued that this impacted the quality of interview data. Participants may have not had enough opportunities to build knowledge and extensive experiences in the field. Nevertheless, the data offer insight into ECE understandings of inclusion and the role of administration in supporting inclusion at the early career stage.

As I was collecting the research data, it was evident that some of the questions in the interview guide proposed a specific approach to disability and inclusion which may have lead responses to follow the direction initiated by the researcher. For example, asking questions that include the term "diagnosis" could have lead participants to direct their responses through a medical lens. Further, the pre-existing relationships I had with the participants and our common experiences around administration practice could have also shaped their responses. Their responses may have not promoted deep reflexivity about the structural constraints on inclusion. These constraints impact not only disabled children, but all in the childcare space including ECEs, administrators, other children and their families.

Lastly, although the responses of ECEs did go beyond the medical model, the questions in the interview guide did not specifically investigate relations in the centre and the relational 
aspect of disability. Responses may have differed if questions and prompts in the interview guide directed focus on systemic influences or relational aspects of disability.

\section{Conclusion}

The objective of the research study was to explore how ECEs understand inclusion and their perceptions of how administration influences their understandings and practice towards inclusion. Three participants were recruited for one-on-one in-depth interviews, including 1current ECE and 2 former ECEs. Collected data from these interviews suggested 3 themes, definitions of disability, perceptions of inclusion, and understandings and opinions towards administration.

Using literature around these topics, I argued that ECEs perceptions of inclusion are influenced by their understandings of disability. These perceptions then lead ECEs to seek certain supports from their administration. After explaining this link, I then questioned who is truly benefitting from these perceptions of inclusion. Finally, I suggested implications for ECEs as a result of the study's findings. I argue that moving towards definitions of disability that are supported by Disability Studies can influence more inclusive practices in our early learning settings. 
APPENDIX A

\section{RESEARCH PARTICIPANTS NEEDED}

“Early Childhood Educators' Understandings of Inclusion and How Their Understandings and Practices are Shaped by Administration"

Are you a current or previous Early Childhood Educator practicing or have practiced in Ontario? We are welcoming 3 current or previous ECEs to participate in a one-on-one indepth interview for a Masters Research Paper presented to the School of Early Childhood Studies, Ryerson University.

\section{Purpose of the Study}

The focus of the research is to explore how previous and current early childhood educators understand inclusion as well as how they perceive the administrative teams they work(ed) with shape their understanding and practice of inclusion. I am seeking to conduct individual interviews with 3 participants. The goal of this study is to better understand inclusion within

early learning centres and how early childhood educators perceive the impact of administration on the centre's inclusive practices.

\section{Example questions include:}

- In your own words, how would you describe your attitude towards including children with disabilities into general learning environments? 


\section{Please consider participating if you are:}

1. $18+$ of age,

2. English speaking

3. Located in the Greater Toronto Area,

4. A Registered Early Childhood Educator with the College of Early Childhood Educators, or previously practiced as an Early Childhood Educator at an early learning environment.

5. Practicing or have practiced in Ontario

* Experience with children with disabilities is preferred but will not be an aspect determining your inclusion/exclusion in the study $*$

\section{The study will not include individuals who...}

1. Are or have only practiced as early childhood assistants, support staff, casual supply staff, long term employment staff, full-time ECE student, or early childhood educators in a Full-Day Kindergarten program.

2. Do not wish to be audio recorded

3. Are current practicing ECEs but not registered with the 
College of Early Childhood Educators.

4. Do not provide consent

\section{Voluntary Participation and Withdrawal:}

If you agree to volunteer, you will be asked to travel to Ryerson University in Toronto on one occasion in July 2019 for 2.50 hours to participate in the study. Participation in this study is completely voluntary. You can choose whether to be in this study or not. If any questions make you uncomfortable, you can skip that question. You may also stop participating at any time. As an incentive, you will receive a $\$ 10$ gift card to Starbucks or Tim Hortons at the end of the interview. If you choose to withdraw from the study, you will still receive this gift card. Prior to your participation in the study, the researcher will go over the consent letter with you. If you do not wish to be audio-recorded, you will not be able to participate in the study. If you wish to withdraw from the study, the researcher will ask to keep your already collected data. If you do not wish for your identifiable data to be included in the study (interview data), the researcher will destroy it immediately. You will have 5 days after your interview to withdraw your interview data from the research. After this time, you will be unable to withdraw your data. All non-identifiable data, such as reflection notes created by the researcher after your interview will be kept.

If you are a potential participant and have a previous relationship with the researcher, we would like to inform you 
that your participation is completely voluntary and will not impact any already existing or future relationships with the researcher: Warda Batool, the Supervisor: Dr. Esther Ignagni or Ryerson University.

\section{Confidentiality}

The researcher will treat participants personal information respectfully and confidentially. Pseudonyms will be used for every participant's name or place they disclose and their privacy will be protected. This includes sensitive personal information that participants would not want to disclose to others or make public during the research process, such as identifiable information and data. To ensure that the privacy of participants is being respected, confidential research will be conducted and properly safeguarded. The information will be locked and stored in a secure location, while only the researchers will have access to it. Data will be shared between researcher and research supervisor using Google Docs, protected with Ryerson email password encrypted as saved password protected files with 2 factor Authenticator. Audio recordings from the interviews will only be listened to by researcher and research supervisor and will be destroyed from researcher's audio recording device immediately after transcription. The interviews will take place in private study rooms within Ryerson University's Student Learning Centre. The door will be kept closed and the rooms will be booked for longer than expected time to avoid disturbances from other students. 
This study has been reviewed and approved by the Ryerson Research Ethics Board.

Protocol \# 2019-227 If you are interested in participating in this research study and/or have any questions, please contact:

Warda Batool, warda.batool@ryerson.ca 


\section{APPENDIX B}

\section{Ryerson University Consent Agreement}

You are being invited to participate in a research study. Please read this consent agreement so that you understand what your participation will involve. Before you consent to participate, please ask any questions to be sure you understand what your participation will involve.

\section{TITLE OF THE STUDY}

“Early Childhood Educators' Understandings of Inclusion and How Their Understandings and Practices are Shaped by Administration"

\section{INVESTIGATORS}

This research study is being conducted by Graduate Research Student: Warda Batool, School of Early Childhood Studies and Research Supervisor: Dr. Esther Ignagni, School of Disability Studies, Ryerson University.

If you have any questions or concerns about the research, please feel free to contact. Researcher: Warda Batoolwarda.batool@ryerson.ca

Research Supervisor: Dr. Esther Ignagni eignagni @ ryerson.ca

Should you have any questions regarding this study's ethical review, please feel free to contact the Research Ethics Board at 416-979-5000 ext. 4841.

Protocol Number: 2019-227

\section{PURPOSE OF THE STUDY}

With your participation, we will explore how early childhood educators understand inclusion and how they perceive the impact that administration has on their early years centre's inclusion practices as well as their own understandings of inclusion. We are inviting you to participate in 
this study as one of three early childhood educators who are currently or have previously been employed at an early childcare setting. Your participation will consist of 1 in-depth interview. The analyzed research data will then be presented in a Master's Research Paper presented to the School of Early Childhood Studies, Ryerson University.

\section{Inclusion Criteria}

For our study, we welcome any early childhood educator that is currently registered with the College of Early Childhood Educators or has previously worked in a childcare centre or preschool as a full-time employee. Individuals must be $18+$ of age, any race, any socio-economic background, any ability, any ethnicity, must be English speaking, and located in the Greater Toronto Area. Additionally, experience working with children with disabilities is preferred but will not be an aspect determining your inclusion/exclusion in the study.

\section{Exclusion Criteria}

For the purpose of this study, we will not be recruiting anyone who is or has only practiced as an early childhood assistant, support staff, causal supply staff, long term employment staff, or fulltime ECE student. It is also preferred that you have practiced in an early childcare setting within Ontario. As we ask potential participants to provide their consent for the study, those who do not will be excluded from the study. Additionally, as our research method involves audio recording of individual interviews, potential participants who do not want to be audio recorded will also be excluded from the study.

\section{DETAILS OF YOUR PARTICIPATION}

- Partaking in a one-on-one in-depth interview to speak about your understanding of inclusion and expand on how your understandings and practices have been shaped by the administrative practices at your early learning centre(s) 
o Questions in the interview will be specifically related to the research topic and are open ended

o Example question: In your own words, how would you describe your attitude towards including children with disabilities into general learning environments?

- Interviews may take 1.5 - 2 hours. However, we ask you to commit up to 2.5 hours of your time as this will ensure time for reviewing the consent agreement or discussing any questions before the interview.

- This study offers participants the option of reviewing their individual interview transcripts before the researcher continues with the study.

- If you choose to withdraw from the study, you will have the option to consent to have your already collected data used for the study. You will also have the option to have your already collected data destroyed immediately. Non-identifiable data such as reflection notes created after your interview will not be destroyed. Participants have 5 days after the interview to withdraw their interview data. After this time, you will no longer be able to withdraw your interview data. - Your participation will also involve access to the study through the RULA Digital Repository, where you can view the final Masters Research Paper. This is optional and you are not required to view the final product of the study.

\section{DATA STORAGE}

An electronic application 'Voice Notes - Secure Notes' will be used to audio record the interviews. This application is password protected, Touch ID protected and only accessible by the researcher. The application will be downloaded on the researcher's mobile device which is Touch ID protected. The data collected for this study includes: signed consent forms from participants (hardcopy or digital), participant information (email), reflection notes created by the researcher after each interview, and audio recordings of interviews that will later be transcribed. 
For the purpose of this research as a master's research paper, interview data collected will be kept for 1 year (transcriptions, reflection notes). This will allow for data to inform future related research and be included in dissemination products. After this time, all research data will be deleted from Google Drive and hard copies (consent forms) will be destroyed by shredding them. Audio recording will only be kept until transcription process is complete and will immediately be destroyed from researcher's audio recording device. Participant information (email) will be destroyed immediately after the interview.

\section{RATIONALE FOR INFORMATION COLLECTION}

All demographic data will be kept confidential and stored securely until interview is complete. Data will only be used when contacting participants regarding the study and during exclusion process. Email addresses will be used when contacting participants regarding details about the study (location, consent letters). All electronic data will be secured through Google drive password protected with Google 2 factor authentication. Any recruited participants who are not eligible or do not get chosen for the study will have their information (email address) destroyed immediately.

\section{INCENTIVE}

As an incentive for your participation, you will receive a $\$ 10$ gift card to Starbucks or Tim Hortons at the end of the interview. You may select one gift card from either of the coffee shops. If you choose to withdraw from the study, you will still receive this gift card.

\section{POTENTIAL RISKS TO YOU AS A PARTICIPANT}

The research study contains some foreseeable risks and it is highly unlikely that you will suffer physical, psychological, or economic harm. However, the questions in the interview will be semi-structured and it is unpredictable whether you may feel uncomfortable as you express their 
thoughts and opinions. At this moment, we would like to inform you of the potential for discomfort and if you feel uncomfortable, you may skip answering a question or stop participation, either temporarily or permanently.

Psychological Risk: The psychological risk to you as a participant is low/minimal. It is possible that you may feel uncomfortable or anxious about participating in a one-on-one interview and/or being audio recorded. You may also feel uncomfortable being interviewed about your current or previous work environment.

- In order to minimize any psychological risk, participation in interviews is completely optional. Discussions with participating ECEs will be done individually so they are not feeling judged or pressured by other participants. The in-depth interviews will hold a relaxed and casual feel, instead of traditional types of interviews. This will help to relieve possible feelings of anxiety or stress. Prior to interview, participants will be assured that the audio recording will only be listened to by primary researcher and research supervisor and that all identifying names will be changed to pseudonyms in the write up. The researcher has many years of experience in interacting with early childhood educators and implementing practice of listening.

Social Risk: There is some social risk when and/or if your participation includes a critique of the administration or colleagues at your centre of current employment or previous employment. You may feel a threat to their relationships with colleagues at current or previous employment.

- The researcher will make every effort to manage this risk by anonymizing the interview data and keeping it confidential (names of colleagues, name of participant, name of employment, location of employment). Further, you will be invited to review your own 
transcripts and can remove anything you feel might be threatening to your social relationships in current or previous employment.

Financial Risk: There is some financial risk when and/or if you choose to critique the administration at the centre of current employment. You may feel a threat to your employment at the current centre.

- The researcher will make every effort to manage this risk by anonymizing the interview data and keeping it confidential (names of colleagues, name of participant, name of employment, location of employment). Further, all you will be invited to review your own transcripts and can remove anything you feel might be threatening to their employment.

Legal Risk: There is some legal risk when and/or if you choose to disclose information that suggests that a child or children with/without disabilities are being subject to abuse or illegal activity at a specific early childcare centre. In this case, the research will have a duty to report and will take the necessary steps to report the information you disclosed.

- The researcher will make every effort to justify the duty to report prior to the interview. Participants will be reminded of the researcher's duty to report before the interview and are encouraged to ask questions relating to this. Additionally, the researcher will anonymize the interview data and keep it confidential (names of colleagues, name of participant, name of employment, location of employment) to ensure the privacy and confidentiality of the participant who disclosed the information leading to the duty to report. Further, you will be invited to review your own transcripts and can remove anything you feel might be threatening. 


\section{POTENTIAL BENEFITS TO YOU AS A PARTICIPANT}

The proposed research may have several benefits to educators who choose to participate.

Through in-depth interviews, educators can possibly receive a safe space to reflect on their own understandings of inclusive practices regarding children with disabilities and their perspectives on how administration shapes their thinking and practice. This can invite them to think about and address feelings and ideas that they may have not before. Additionally, these benefits can lead to proposals for positive change in early childcare centres.

I cannot guarantee, however, that you will receive any benefits from participating in this study.

\section{CONFIDENTIALITY}

The researcher will treat your personal information respectfully and confidentially. Pseudonyms will be used to ensure that your privacy will be protected, including sensitive personal information that you would not want to disclose to others or make public during the research process. To ensure that your privacy is being respected, confidential research will be conducted and properly safeguarded. All information such as your interview data will be locked and stored in a secure location, while only the researcher and research supervisor will have access to it. All digital data will only be shared between the researcher and research supervisor through Google Docs, protected with Ryerson email password encrypted as saved password protected files with 2 factor Authenticator.

\section{COSTS OF PARTICIPATION}

Costs for your participation may include your travel to and from the interview location: Ryerson University Student Learning Centre 341 Yonge St, Toronto, ON M5B 1S1. COMPENSATION FOR INJURY 
By agreeing to participate in this research, you are not giving up or waiving any legal right in the event that you are harmed during the research.

\section{VOLUNTARY PARTICIPATION AND WITHDRAWAL}

Participation in this study is completely voluntary. You can choose whether to be in this study or not. If any questions make you uncomfortable, you can skip that question. You may stop participating at any time. If you choose to withdraw from the study, you will have the option to allow your already collected data used for the study. You will also have the option to have your already collected data destroyed immediately. Your choice of whether or not to participate will not affect your current or future relations with Ryerson University or the investigators: Warda Batool and Dr. Esther Ignagni.

\section{CONFLICT OF INTEREST}

For participants who have already existing relationships with the researcher: colleague to colleague or friend to friend, we would like to take this opportunity to remind you that you are not obliged to commit your participation in this study. Additionally, if you choose to decline your consent, withdraw from a question(s) or the interview, your already existing relationship with the researcher will not be impacted.

\section{INTERVIEW LOCATION}

Individual interviews will be held at Ryerson University Student Learning Centre, 341 Yonge St, Toronto, ON M5B 1S1. Rooms to be determined post recruitment.

\section{NEXT STEPS}

If you are interested in participating in this study, you may return a signed copy of this letter to the researcher: Warda Batool, warda.batool@ ryerson.ca . You may also bring a signed copy on 
the day of the interview or sign a hard copy provided by the researcher on the day of the interview.

\section{QUESTIONS ABOUT THE STUDY}

If you have any questions about the research, please ask.

You may contact,

Principal Investigator/ Graduate Studies Researcher: Warda Batool warda.batool@ryerson.ca

Research Supervisor: Dr. Esther Ignagni

eignagni@ryerson.ca

This study has been reviewed by the Ryerson University Research Ethics Board. Protocol Number: 2019-227.

If you have questions regarding your rights as a participant in this study, please contact:

Research Ethics Board

c/o Office of the Vice President, Research and Innovation Ryerson University

350 Victoria Street, Toronto, ON M5B 2K3 416-979-5042 rebchair@ryerson.ca 
“Early Childhood Educators' Understandings of Inclusion and How Their Understandings and Practices are Shaped by Administration"

\section{PARTICIPATION: CONFIRMATION OF AGREEMENT}

Your signature below indicates that you have read the information in this agreement and have had a chance to ask any questions you have about the study. Your signature indicates that you agree to participate in the study and have been told that you can change your mind and withdraw your consent to participate at any time. You have been given a copy of this agreement. You have been told that by signing this consent agreement you are not giving up any of your legal rights.

Name of Participant (please print)

Signature of Participant

Date

\section{AUDIO RECORDING: CONFIRMATION OF AGREEMENT}

Your signature below indicates that you have read the information in this agreement and have had a chance to ask any questions you have about the study and its method of audio recording individual interviews. Your signature indicates that you agree to the audio recording of your interview and have been told that you can change your mind and withdraw your consent to be audio recorded at any time. You have been given a copy of this agreement. You have been told that by signing this consent agreement you are not giving up any of your legal rights.

Name of Participant (please print) Signature of Participant

Date 


\section{APPENDIX C}

\section{Interview Guide}

\section{Interview Number:}

\section{Participant's Pseudonym:}

1. What does inclusion or inclusive practice mean to you?

- Can you give any examples that capture your understandings of inclusion? What was ‘inclusive' about these scenarios/examples?

- Can you share a story of when inclusion did not work? Why do you think this happened?

2. Can you explain your approach to including children with or without diagnosed disabilities and designations?

- Can you think of any examples in your practice that capture your views in regard to inclusive practices? How were these children included? If they were not, why?

- Can you think of practices you have created or altered to specifically foster inclusion? How have these practices worked? If not, why?

3. In your own words, can you describe the role and responsibilities of your centre/schools administrative team and/or supervisor?

- Can you explain the effectiveness of these roles and responsibilities? Why do you think this?

4. What are your experiences with the administrative supports in your centre?

- Can you think of a relevant experience that you wish you never had? Can you think of an experience you would classify as 'excellent'?

- Can you think of supports that you wish you would have received? Why do you wish for these? 
5. What do you recall about the professional development you receive in regard to inclusion?

- Can you explain how your professional development trainings are structured and what they contain?

- What are aspects of your professional development that you find beneficial? What are the aspects you would wish to change?

6. Thinking about your professional development experiences, what have you learned about inclusive practice? How has professional development changed your thinking. If not, why? How did your practice change? If not, why?

- Can you recall relevant examples that would vouch for the change in thinking and practice as a result of professional development?

7. What are other resources provided by your administrative team? Prompt - funding, time, external PD opportunities etc.

- How do these resources/supports foster your thinking and practice?

- How do these resources impact the way your view disability and difference?

8. In your centre/school, describe any requirements you have to participate in any professionally related workshops? If not, why?

9. Can you describe your relationship with your administration or supervisor?

- Can you describe any scenarios that portray the relationship you have with your administration and/or supervisor?

- How does this relationship impact you in requesting supports to grow your thinking and practice? 
- Can you describe any aspects of this relationship that you wish were different? If so, why do you wish for this?

10. Can you describe any opportunities you have to provide feedback on the supports you receive?

- What do you think about the effectiveness of these opportunities?

- How do you see staff feedback taken into consideration? If not, why?

- Can you explain any changes you would wish to make in opportunities for staff feedback? 


\section{References}

Balakrishnan, A., Kulkarni, K., Moirangthem, S., Kumar, CN., Math, SB. \& Murthy, P. (2019) The rights of persons with disabilities Act 2016: Mental health implications. Indian J Psychol Med, 41.119-25. Retrieved from http://www.ijpm.info/article.asp?issn=0253-7176; year=2019; volume=41;issue=2; spage= $119 ;$ epage $=125 ;$ aulast $=$ Balakrishnan

Braden, J. P., Huai, N., White, J. L., \& Elliott, S. N. (2005). Effective professional development to support inclusive large-scale assessment practices for all children. Assessment for Effective Intervention, 31(1), 63-71. doi:10.1177/073724770503100106

Brooker, M., \& Cumming, T. (2019). The 'dark side' of leadership in early childhood education. Australasian Journal of Early Childhood, 44(2), 111-123. Retrieved from https://doi.org/10.1177/1836939119832073

Bruns, D. A., \& Mogharreban, C. C. (2007). The gap between beliefs and practices: Early childhood practitioners' perceptions about inclusion. Journal of Research in Childhood Education, 21(3), 229-241. doi:10.1080/02568540709594591

City of Toronto. (2007). Inclusion: Policy development guidelines for early learning and care programs. Retrieved from https://connectability.ca/Garage/wpcontent/uploads/2013/10/policy_inclusion.pdf

College of Early Childhood Educators. (2019). CPL program. Retrieved from https://www.college-ece.ca/en/Members/CPL-Program

Curran, T., \& Runswick-Cole, K. (2013). Disabled children's childhood studies: Critical approaches in a global context. Palgrave Macmillan. 
Damianidou, E. \& Phtiaka, H. (2018). Implementing inclusion in disabling settings: The role of teachers' attitudes and practices. International Journal of Inclusive Education, 22(10), 1078-1092. doi:10.1080/13603116.2017.1415381

Das, A. K., Gichuru, M., \& Singh, A. (2013). Implementing inclusive education in Delhi, India: Regular school teachers' preferences for professional development delivery modes. Professional Development in Education, 39(5), 698-711. doi:10.1080/19415257.2012.747979

Dreyer, L. M. (2013). Exploring the changing role of learning support teachers in the Western Cape, South Africa. Perspectives in Education, 31(2), 54-64. Retrieved from https://search-proquest-com.ezproxy.lib.ryerson.ca/docview/1566320874?pqorigsite $=$ summon

Edmunds, A. (1998). Classroom teachers are not prepared for the inclusive classroom, Exceptionality Education Canada, 8(2), 27-40.

Elliott, J. (2005). Using Narrative in Social Research. SAGE Publications.

Frankel, E. B. (2004). Supporting inclusive care and education for young children with special needs and their families an international perspective. Childhood Education, 80(6), 310316. doi:10.1080/00094056.2004.10521277

Frankel, E. B., Hutchinson, N. L., Burbidge, J., \& Minnes, P. (2014). Preservice early childhood educators' and elementary teachers' perspectives on including young children with developmental disabilities: A mixed methods analysis. Journal of Early Childhood Teacher Education, 35(4), 373-391. doi:10.1080/10901027.2014.968300 
Frederick, M. P. (2013). "Sit-still and shut-up": The construction of childhood and classroom management pedagogies in a preservice education textbook. Electronic Thesis and Dissertation Repository. 1381. Retrieved from https://ir.lib.uwo.ca/etd/1381

Friendly, M., \& Prentice, S. (2009). About Canada: Childcare. Fernwood Pub.

Frey, B. (2018). The SAGE Encyclopedia of Educational Rresearch, Measurement, and Evaluation, 1-4. Thousand Oaks, CA: SAGE Publications, Inc. doi: $10.4135 / 9781506326139$

Friendly, M. (2004). Next steps on early childhood education and care. Canadian Review of Social Policy, (53), 108-121. Retrieved from https://search-proquestcom.ezproxy.lib.ryerson.ca/docview/222287459?pq-origsite=summon

Goodley, D. (2001). 'Learning difficulties', the social model of disability and impairment: challenging epistemologies, Disability \& Society, 16(2), 207-231. dio:10.1080/09687590120035816

Goodley, D. (2013). Dis/entangling critical disability studies. Disability \& Society, 28(5), 631-644. doi:10.1080/09687599.2012.717884

Goodley, D. (2014). Dis/Ability Studies: Theorising Disablism and Ableism. London: Routledge.

Goodley, D., \& Lawthom, R. (2019). Critical disability studies, Brexit and Trump: A time of neoliberal-ableism. Rethinking History, 23(2), 233-251. doi:10.1080/13642529.2019.1607476

Green, S. E. (2007). "We're tired, not sad": Benefits and burdens of mothering a child with a disability. Social Science \& Medicine, 64(1), 150-163. doi:10.1016/j.socscimed.2006.08.025 
Harman, B. (2014). Inclusion/integration: is there a difference? Canadian Down Syndrome Society. Retrieved from https://cdss.ca/wp-content/uploads/2016/06/CDSS-integrationvs-inclusion.pdf

Holt, K. G., Saltzman, E., Ho, C., \& Ulrich, B. D. (2007). Scaling of dynamics in the earliest stages of walking. Physical Therapy, 87(11), 1458-1467. doi:10.2522/ptj.20060299

Horowitz, L., Jansson, L., Ljungberg, T., \& Hedenbro, M. (2005). Behavioural patterns of conflict resolution strategies in preschool boys with language impairment in comparison with boys with typical language development. International Journal of Language \& Communication Disorders, 40(4), 431-454. doi:10.1080/13682820500071484

Horne, P. E. \& Timmons, V. (2009). Making it work: Teachers' perspectives on inclusion. International Journal of Inclusive Education, 13(3), 273-286. doi:10.1080/13603110701433964

Huang, H., \& Diamond, K. E. (2009). Early childhood teachers' ideas about including children with disabilities in programmes designed for typically developing children. International Journal of Disability, Development and Education, 56(2), 169-182.

doi:10.1080/10349120902868632

Johnson, B., \& Christensen, L. B. (2017). Educational Research: Quantitative, Qualitative, and Mixed Approaches. SAGE Publications, Inc.

Irwin, S. H., Brophy, K., BN, Lero, D. S., \& SpeciaLink: The National Centre for Child Care Inclusion. (2004). Inclusion: The next generation in child care in Canada. Breton Books. Irwin, S. H., \& SpeciaLink: The National Centre for Child Care Inclusion. (2009). The SpeciaLink Early Childhood Inclusion Quality Scale. Breton Books. 
Ishimine, K., Tayler, C., \& Thorpe, K. (2009). Accounting for quality in Australian childcare: A dilemma for policymakers. Journal of Education Policy, 24(6), 717-732. doi:10.1080/02680930903207695

Kafer, A. (2013). Feminist, Queer, Crip. US: Indiana University Press.

Killoran, I., Woronko, D., \& Zaretsky, H. (2014). Exploring preservice teachers' attitudes towards inclusion. International Journal of Inclusive Education, 18(4), 427-442. doi:10.1080/13603116.2013.784367

Leavy, P. (2017). Research Design: Quantitative, Qualitative, Mixed Methods, Arts-Based, and Community Based Participatory Approaches. Guilford Press.

Lehr, A. E. (1999). The administrative role in collaborative teaching. NASSP Bulletin, 83(611), 105-111. doi:10.1177/019263659908361113

Liasidou, A. (2016). Disabling discourses and human rights law: A case study based on the implementation of the UN convention on the rights of people with disabilities. Discourse: Studies in the Cultural Politics of Education, 37(1), 149-162. doi:10.1080/01596306.2014.936928

Majoko, T. (2016). Inclusion in early childhood education: Pre-service teachers' voices. Early Child Development and Care, 186(11), 1859-1872. doi:10.1080/03004430.2015.1137000

Marvin, C., LaCost, B., Grady, M., \& Mooney, P. (2003). Administrative support and challenges in Nebraska public school early childhood programs: Preliminary study. Topics in Early Childhood Special Education, 23(4), 217-228. doi:10.1177/02711214030230040301

McCrimmon, A. W. (2015). Inclusive education in Canada: Issues in teacher preparation. Intervention in School and Clinic, 50(4), 234-237. doi:10.1177/1053451214546402 
McDonald, J. (2018). Twelve tips for teaching child development and disability to medical students. Medical Teacher, 40(2), 135-139. doi:10.1080/0142159X.2017.1365118

McLeskey, J. \& Waldron, N. L. (2002). Professional development and inclusive schools: Reflections on effective practice. The Teacher Educator, 37(3), 159-172. doi:10.1080/08878730209555291

Norrell, L. (1997). A case for responsible inclusion, Teaching Pre K-8, 28(1), 17. Retrieved from http://ezproxy.lib.ryerson.ca/login?url=https://search-proquestcom.ezproxy.lib.ryerson.ca/docview/231934038?accountid=13631

Oliver, M. (2013). The social model of disability: Thirty years on. Disability \& Society, 28(7), 1024-1026. doi:10.1080/09687599.2013.818773

Ontario. (2007). Early learning for every child today: A framework for Ontario early childhood settings. Toronto: Ministry of Children and Youth Services.

Ontario Ministry of Education. (2014). How Does Learning Happen? Ontario's Pedagogy for the Early Years: A Resource About Learning Through Relationships for Those Who Work with Young Children and Their Families. Toronto.

Reaume, G. (2014). Understanding critical disability studies. CMAJ: Canadian Medical Association Journal = Journal De l'Association Medicale Canadienne, 186(16), 1248-1249. doi:10.1503/cmaj.141236

Ritchie, J., \& Lewis, J. (2003). Qualitative research practice: A guide for social science students and researchers Sage Publications.

Rose, S. \& Whitty, P. (2010) 'Where Do We Find the Time to Do This?' Struggling against the Tyranny of Time, Alberta Journal of Educational Research, 56(3), 257-273. 
Ruairc, M. G., Ottesen, E., \& Precey, R. (2013). Leadership for inclusive education. Studies in Inclusive Education, 18. Sense Publishers. Retrieved from https://link-springercom.ezproxy.lib.ryerson.ca/content/pdf/10.1007\%2F978-94-6209-134-4.pdf

Russel, C. S., Allday, R. A., \& Duhon, G. J. (2015). Effects of increasing distance of a one-on-one paraprofessional on student engagement. Education and Treatment of Children, 38(2), 193-210. doi:10.1353/etc.2015.0008

Schön, D. A. (1984). The Reflective Practitioner: How Professionals Think in Action. Basic Books.

Siwik, E. (2013). Early childhood educators' perception of their training and support seeds for inclusive education. Retrieved from Ryerson University Digital Repository.

Shady, S. A., Luther, V. L., \& Richman, L. J. (2013). Teaching the teachers: A study of perceived professional development needs of educators to enhance positive attitudes toward inclusive practices. Education Research and Perspectives (Online), 40, 169-191.

Schanin, M., \& Reiter, S. (2007). From integration to inclusion: The Tirat Carmel center for learning disabilities as a lever for beneficial integration of children with special needs. Childhood Education, 83(6), 347-350. doi:10.1080/00094056.2007.10522948

Shyman, E. (2016). The reinforcement of ableism: Normality, the medical model of disability, and humanism in applied behavior analysis and ASD. Intellectual and Developmental Disabilities, 54(5), 366-376. doi:10.1352/1934-9556-54.5.366

Specht, J. (2013). Introduction to the special issue - what is inclusive education in Canada? Canadian Journal of Education, 36(1). Retrieved from https://ryerson.summon.serialssolutions.com. 
Suc, L., Bukovec, B., Zveglic, M., \& Karpljuk, D. (2016). Primary school teachers' attitudes towards inclusive education in Slovenia: A qualitative exploration. RUO. Revija Za Univerzalno Odlicnost, 5(1), 30-46.

Thomas, C. (2004). Rescuing a social relational understanding of disability. Scandinavian Journal of Disability Research, 6(1), 22-36. doi:10.1080/15017410409512637

Underwood, K. (2013). Everyone is Welcome: Inclusive Early Childhood Education and Care. Queen's Printers for Ontario.

Underwood, K. \& Frankel, E. (2012). Early Intervention in Canada: The Developmental Systems Model in Ontario. Infants \& Young Children, 25(4), 286-296.

Underwood, K., Valeo, A., \& Wood, R. (2012). Understanding inclusive early childhood education: A capability approach. Contemporary Issues in Early Childhood, 13(4), 290299. https://doi.org/10.2304/ciec.2012.13.4.290

Wien, C.A. (1996). Time, Work, and Developmentally Appropriate Practice, Early Childhood Research Quarterly, 11, 377-403. http://dx.doi.org/10.1016/S0885-2006(96)90013-7

Williams, K. J., \& Murray, D. W. (2015). Negotiating the normative: The other normal for mothers of disabled children. Journal of Family Studies, 21(3), 324-340. doi:10.1080/13229400.2015.1098560

Woodcock, S., \& Woolfson, L. M. (2019). Are leaders leading the way with inclusion? teachers' perceptions of systemic support and barriers towards inclusion. International Journal of Educational Research, 93, 232-242. doi:10.1016/j.ijer.2018.11.004

Zagona, A. L., Kurth, J. A., \& MacFarland, S. Z. C. (2017). Teachers' views of their preparation for inclusive education and collaboration. Teacher Education and Special Education, 40(3), 163-178. doi:10.1177/08884064176929 